\title{
Differential thermal expansion as a cause of salt decay: literature review, experiments and modelling of micro and macro effects on Ançã limestone
}

\begin{abstract}
Salt decay is one of the harshest, most frequent and more complex types of decay of porous materials in built heritage, including natural stones, ceramics and mortars. In this article, we address the mechanism of thermal expansion which is one of the least studied, yet most controversial, of those proposed over time to explain salt decay. We present a review of scientific literature on the topic, followed by a study of the effects of thermal expansion on a specific material, the well-known Ançã limestone. The study included experimental measurement of the linear thermal expansion coefficient of the Ançã, both in its natural state and with varying contents of sodium chloride, sodium sulphate or sodium nitrate. The results show that this coefficient: (i) is significantly higher when the stone is contaminated with salt; (ii) scales approximately with the amount of salt contained in the stone pores, regardless of the type of salt. Based on these results and on modelling of damage modes at the microscopic and macroscopic levels respectively, we conclude that thermal expansion can cause powdering, disaggregation or other types of decay consisting in internal loss of cohesion. However, it is not likely to cause exfoliation of salt loaded layers.
\end{abstract}

Keywords: Thermal expansion; Ançã limestone; Soluble salts; Sodium chloride; Sodium sulphate; Sodium nitrate; Exfoliation; Powdering; Disaggregation

\section{Introduction}

Soluble salts cause harsh and recurrent damage to porous building materials and yield some of the most difficult problems posed to the conservation of our built heritage. Part of the difficulty stems from the complexity of the underlying processes that, after decades of research, have not yet been fully understood.

Several mechanisms have been proposed over time to explain salt-induced damage. The main three are crystallization pressure, hydration pressure and differential thermal expansion (Cooke \& Smalley 1968). The first, crystallization pressure, results from the force exerted on pore walls by the growing crystals, and is currently considered the most relevant salt decay mechanisms (Flatt et al. 2014). In contrast, the second mechanism, hydration pressure, has been widely dismissed as such. Hydration can increase the volume of salt crystals by incorporation of water molecules. However, it was realized that in reality it consists of dissolution of the anhydrous phase followed by recrystallization of the hydrated phase. This was shown for sodium sulphate by authors such as Charola and Weber (1992), MacMahon et al. (1992) or RodriguezNavarro et al. (2000).

In contrast, there are still many doubts regarding the third mechanism, thermal expansion. This mechanism is proposed because most salts, in their crystalline form have higher thermal expansion than porous building materials such as natural stone, mortars or ceramics. Therefore, when salt is present in the material pores, temperature variations could, in principle, cause differential expansion of the crystals in 
relation to the porous matrix. This would introduce internal stresses in the material, eventually leading to exfoliation or microscopic disintegration, as depicted in Fig. 1. Strikingly, however, very little research has been conducted on the role of thermal expansion within salt decay. The topic is mentioned sporadically in the literature, though mostly as a hypothesis, but the opinions are often contradictory and there are still no definitive conclusions.
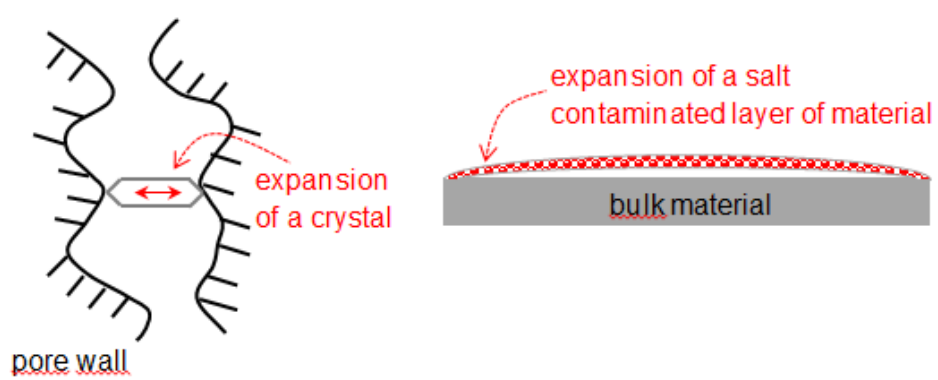

Fig. 1 - Possible effects of thermal expansion at the micro and macro levels, respectively: a) pressure of a salt crystal in a pore; b) detachment of a salt-contaminated surface layer of the material, i.e., exfoliation

The present article aims to fill this research gap. It presents a review of scientific literature on the mechanism of thermal expansion, followed by a study of its effects on a specific material, the well-known Ançã limestone. Ançã can be found in many classified monuments in Portugal and is very susceptible to salt decay (Costa \& Delgado Rodrigues 2012), as illustrated in Figs. 2 and 3. Since in Portugal, as in other regions of Europe, monuments are normally subjected to significant temperature variations, it is important to clarify whether thermal expansion is a relevant factor in the salt decay processes these monuments undergo. Indeed, salt decay problems are recurrent in architectural heritage. Furthermore, they are expected to get worse as climate change predictions anticipate more frequent extreme weather events. These include precipitation followed by droughts, which will intensify crystallization and its accumulation in materials, and higher temperatures, which will increase the effects of thermal expansion (Benavente et al. 2008; Sabbioni et al. 2010).
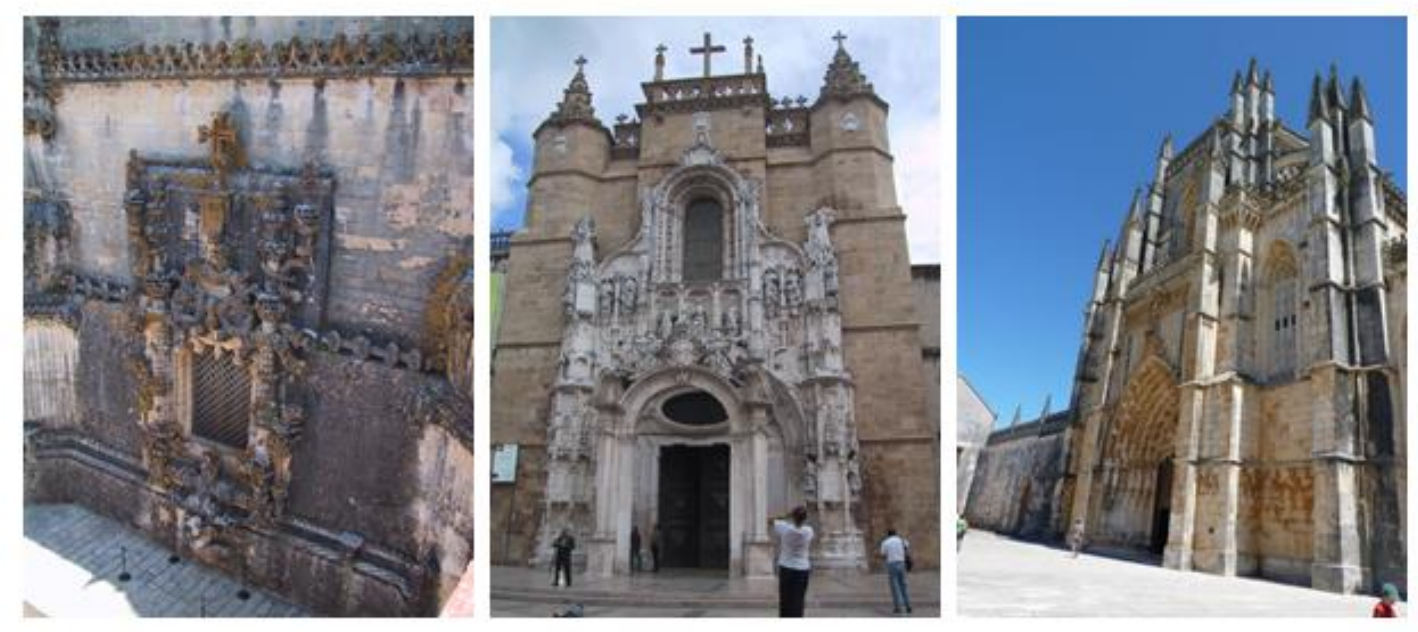

Fig. 2 - Some monuments in Portugal where Ançã limestone can be found: Convent of Christ, in Tomar (left), Santa Cruz Church, in Coimbra (middle) and Batalha Monastery (right). 


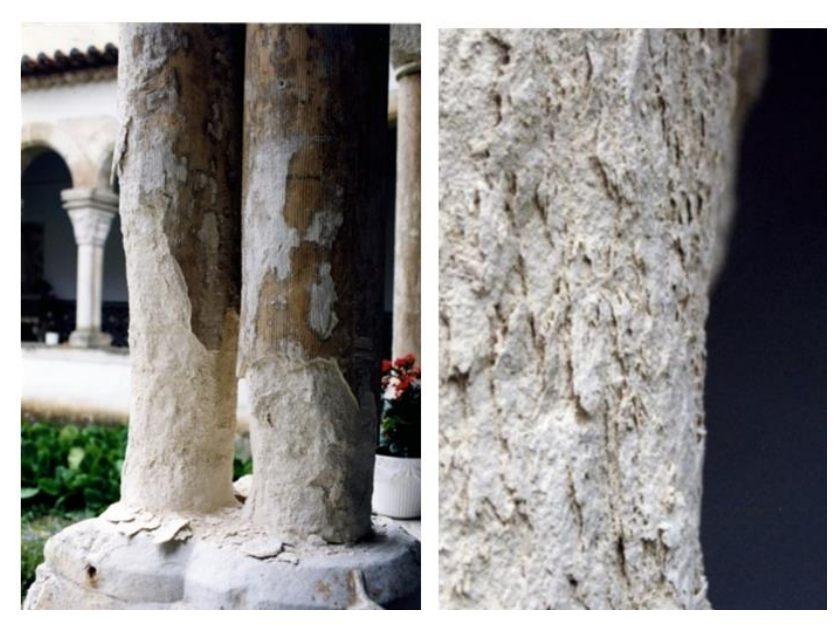

Fig. 3 - Ançã stone columns at the cloister of Santa Cruz Monastery (left) and detail of their decay pattern (courtesy of J. Delgado Rodrigues).

The study we present is based on experimental measurement of the linear coefficient of thermal expansion of Ançã stone, before and after contamination with sodium chloride, nitrate or sulphate. The raw data of the experimental measurements are presented in the Appendix.

The linear thermal expansion coefficient describes how the length of a sample changes as the temperature varies. Also frequently used is the volumetric thermal expansion coefficient, which refers to the change of the sample in volume. However, in this article, the linear coefficient is always meant.

This type of data is essential to evaluate how salt affects the thermal expansion of a given material. However, obtaining it experimentally, as we did, is laborious and expensive (which is why only rarely it has been carried out, as we will show in the literature review). For this reason, our work included also the validation of two mathematical models that predict the thermal expansion coefficient as a function of salt content.

We then tackle the central question of whether thermal expansion could cause damage to Ançã stone, at the microscopic or macroscopic levels. First, we express the conceptual models in Fig. 1, graphically and then analytically. Afterwards, we apply those models to the case in which the Ançã is contaminated with sodium chloride, sulphate or nitrate, which allowed us to reach very clear conclusions on the damage potential of thermal expansion. Lastly, we indicate key topics to be explored in the future and, at the end of the article, summarize and put in perspective the main conclusions.

\section{Literature review}

The idea that thermal expansion could be relevant in the context of salt decay can be traced back at least to Schaffer (1932). In his early text about the weathering of natural stone in buildings, the author defends, citing a communication with Scott Russel',, that the stresses produced by the differential thermal expansion of surface skins of gypsum could cause limestone delamination. This would happen because the linear thermal expansion coefficient is five times greater for gypsum than for calcite.

The question of whether differential thermal expansion is a relevant salt decay mechanism continued to sporadically appear in the scientific literature, particularly from 1965 on, but the opinions are contradictory. Some authors argue that it is, several defending that its effects will add to those of salt crystallization, but still others say it is not. 
Wellman and Wilson (1965) expressly dismissed the relevancy of thermal expansion as a cause of the cavernous weathering of rocks in the dry valleys of Antarctica. They based their conclusion on the observation that the insides of the holes, whose surface was covered by salt, are less exposed to direct sunlight. Therefore, they attributed the weathering to salt crystallization.

Differently, Cooke \& Smalley (1968) defended that salt thermal expansion could be one of the factors leading to the disintegration of rock in deserts, and that its effects would add to those of crystallization. They pointed out that daily ranges up to $54^{\circ} \mathrm{C}$ in air temperature and of much more in surface temperatures can easily occur in deserts. And that a temperature change of $54^{\circ} \mathrm{C}$ gives an expansion considerably greater for a common desert salt such as $\mathrm{NaCl}$, than for rocks like, for example, granites. Therefore, the thermal expansion of the salt in confined spaces like the rock pores can result in stresses that may disintegrate the material.

Evans (1969-1970) supported the view that the effects of thermal expansion can add to those of crystal growth. Also referring to the case of rock disintegration in deserts, he pointed out that "when all the solution has evaporated, the dry rock surface heats up rapidly", and held that it was necessary to experimentally test this hypothesis.

Johnston (1973) too thought that thermal expansion was an additive mechanism to crystallization. Like Wellman and Wilson, he carried out observations of granite tafoni in the dry valleys of Antarctica. However, contrary to them, Johnston concluded that thermal expansion played a relevant role in the decay. He did not discuss the objection of Wellman and Wilson, that the internal surface of the tafoni, from which damage progresses, has little exposition to direct sunlight. But he carried out XRD analyses which showed that $\mathrm{NaCl}$ was the main salt present on those surfaces. He then argued, like Cooke \& Smalley, that a temperature change of $54^{\circ} \mathrm{C}$, which is within the normal range of air temperature in deserts, would produce a much greater volumetric change in $\mathrm{NaCl}$ than in granite. Differential expansion could, thus, lead to flacking, especially if the rock was already weakened by fissures and cracks.

The first experimental simulations of thermal expansion of salts in stone decay were carried out by Goudie (1974). These experiments were performed on sandstone and chalk, using $3 \mathrm{~cm}$ cubes. The cubes were filled with saturated solution of $\mathrm{NaNO}_{3}$, oven dried and then subjected to either of two types of temperature cycling: (i) 43 to 58 cycles of 6 hours at $60^{\circ} \mathrm{C}$ plus 18 hours at $30^{\circ} \mathrm{C}$, in an oven; (ii) 2160 cycles under an infrared heater, each cycle comprising one hour at $60^{\circ} \mathrm{C}$ followed by another hour at $20^{\circ} \mathrm{C}$. Goudie also conducted crystallization experiments under condition (i), which caused great damage. Yet, none of the thermal expansion regimes produced measurable changes in any of the stones, which led the author to conclude that thermal expansion is ineffective as a weathering mechanism. However, Goudie would later put these results into perspective, in his seminal book with Viles, holding that much more work was required before the potential of thermal expansion could be effectively dismissed (Goudie and Viles 1997).

Chapman (1980) too concluded that thermal expansion is probably not a relevant mechanism of rock disintegration by $\mathrm{NaCl}$ in the Saudi Arabian desert. He based this conclusion on his observations that disintegration was in general as rapid on rock faces sheltered from the hot sun as it was on faces exposed directly to the sun, and occurred also in deep caves where temperature ranges are expected to be minimal.

In contrast, Johannessen et al. (1982) argued that thermal expansion can be a primary cause of rock weathering in the North-tempered Oregon, increasing the retreat of ocean cliffs. The conclusion is based on their observations that, in the salt spray zone (i.e. a zone not directly subjected to wave attack), cliffs weathered more rapidly on sunny than on shadowy exposures. 
Johannessen et al. did not take into account that evaporation and, thus, crystal growth could also be faster on sunny exposures due, for example, to wind or insolation itself. But they backed their conclusion with calculations of the stress generated by the constrained thermal expansion of a system of adjacent sodium chloride and quartz crystals. This was, to the best of our knowledge, the first time that mathematical considerations beyond back-of-the envelope calculations were used to investigate the effects of differential thermal expansion. Moreover, it was, until now, the only time that such considerations were used to assess whether a specific material could be damaged by the thermal expansion of a specific salt.

The calculations presented by Johannessen et al. can be reproduced if we apply Eqs. 1 and 2 to the simplified geometry depicted in Fig. 4. Eq. 1 gives the unrestrained linear thermal expansion $\Delta \mathrm{I}^{\top}(\mathrm{m})$ of a body subjected to a temperature raise $\Delta T$, whereas Eq. 2 gives the linear compression $\Delta \mathrm{I}^{\mathrm{P}}(\mathrm{m})$ of a body when a force $P$ is applied on it. Therefore, when expansion is restrained, the pressure $P$ generated by a temperature raise $\Delta T$ can be obtained by equalizing the total expansion that the system would experience if both crystals could expand freely $\left(\Delta \mathrm{l}^{\top} \mathrm{NaCl}^{+}{ }^{-} \mathrm{l}^{\top}{ }_{\mathrm{SiO} 2}\right)$ and the compression needed to cancel that expansion $\left(\left.\Delta\right|^{P}{ }_{\text {NaCl }}+\Delta I^{P}\right.$ Sio2 $)$, as expressed by Eq. 3.

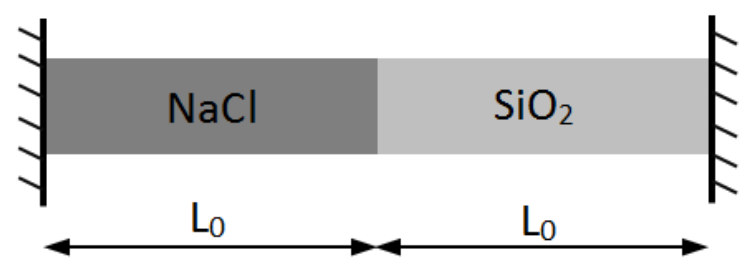

Fig. 4 - Possible geometry of the system considered by Johannessen et al. (1982) to estimate the pressure generated by constrained thermal expansion of adjacent sodium chloride and quartz crystals

$\Delta l^{T}=\alpha \times L_{0} \times \Delta T$

in which $\alpha(/ \circ \mathrm{C})$ is the coefficient of linear thermal expansion, $L_{0}(\mathrm{~m})$ the initial length and $\Delta T\left({ }^{\circ} \mathrm{C}\right)$ the temperature range.

$\Delta l^{P}=k \times L_{0} \times P$

in which $k(/ \mathrm{Pa})$ is the linear compressibility and $P(\mathrm{~Pa})$ the applied pressure (GSE 1970-1979).

$\Delta l^{T}{ }_{\mathrm{NaCl}}+\Delta l_{\text {SiO2 }}^{T}=\Delta l^{P}{ }_{\mathrm{NaCl}}+\Delta l_{\mathrm{SiO} 2}^{P}$

Johannessen et al. assumed that the compressive strength of sandstones can vary from 10 to $187 \mathrm{MPa}$ and is limited by the resistance of its cement matrix, whereas that of sodium chloride crystals can vary from 26 to $38 \mathrm{MPa}$. They concluded that a temperature raise of $50^{\circ} \mathrm{C}$, which results in a compressive stress of $97 \mathrm{MPa}$, is then sufficient to break a quartz crystal out of its cementing matrix in the weaker sandstones.

Eight years later, Larsen and Nielsen (1990) studied the powdering of ceramic brick in medieval churches in Jutland, Denmark. The authors found out that (i) the medieval bricks were contaminated with $\mathrm{NaCl}$ and that (ii) $\mathrm{NaCl}$ can significantly increase the thermal expansion of bricks. Conclusion (ii) was based on experimental measurement of the linear thermal expansion coefficient of brick with different $\mathrm{NaCl}$ content, before and after salt contamination. These two conclusions suggested that thermal expansion could be a cause of the powdering. 
Larsen and Nielsen noted that the linear thermal expansion coefficient exhibited a practically linear variation with salt content. In the article, they use their experimental data to positively validate a model, originally been put forward by Nielsen (1988), to calculate the coefficient of linear thermal expansion as a function of salt content. The model is a sphere of tile with a central spherical pore filled with $\mathrm{NaCl}$. Since the salt has a higher thermal expansion coefficient than the tile, thermal expansion results in compression of the salt and outward traction of the tile shell. Thermal expansion is assumed to be linear (Eq. 1) in the radial direction, which leads to the equilibrium condition in Eq. 4. From this, the analytical expression of the model depicted in Eqs. 5 to 9 was derived, as explained in Nielsen (1988).

$$
\Delta l^{T}{ }_{\text {NaCl }}+\Delta l^{P}{ }_{\text {NaCl }}=\Delta l^{P}{ }_{\text {tile }}+\Delta l^{T}{ }_{\text {itle }}
$$

in which $\Delta I^{T}(\mathrm{~m})$ and $\Delta I^{P}(\mathrm{~m})$ have the same meaning as before.

$$
\frac{\alpha^{*}}{\alpha^{b}}=1+\frac{2 \times c \times n \times(m-1)}{(A+n)(1+c)}
$$

in which

$$
A=\frac{1-c}{1+c}
$$

$$
m=\frac{\alpha_{s}}{\alpha_{b}}
$$

$n=\frac{E_{s} \times\left(1-c^{\prime}\right)}{E_{b} \times\left(1+c^{\prime}\right)}$

$c^{\prime}=1-M S C \times \frac{(1-c) \times \rho_{b}}{c \times \rho_{s}}$

In these equations, $\alpha^{*}\left[\mathrm{~T}^{-1}\right]$ is the thermal expansion coefficient of the salt contaminated brick, $c[-]$ the volume fraction porosity of the brick and MSC [-] the mass fraction salt content, whereas $\alpha_{s}$ and $\alpha_{b}\left[T^{-1}\right]$ are the thermal expansion coefficients, $E_{s}$ and $E_{b}\left[\mathrm{M} \mathrm{L}^{-1} \mathrm{t}^{-2}\right]$ the Young's moduli and $\rho_{s}$ and $\rho_{b}\left[\mathrm{M} \mathrm{L}^{-3}\right]$ the dry density of salt and brick, respectively. The thermal expansion coefficient of the salt was experimentally measured using rock-salt made of pure $\mathrm{NaCl}$, and was found to be six times greater than that of the uncontaminated brick.

Some months later, Rossi-Manaresi and Tucci (1991) raise the interesting possibility that salt deposition, instead of being disruptive, can have a cementing effect when crystallization pressure is lower than the mechanical strength of the material. In this case, damage would arise later due to the differential behaviour between the contaminated and non-contaminated layers of material, a process in which thermal expansion would be the primary degradation mechanism.

This cementing effect of soluble salts was very clear on an old façade adjacent to Alhos Vedros tide-mill, in Portugal (Diaz Gonçalves et al. 2006, Diaz Gonçalves 2007). The alveolar decay pattern observed there could not have developed if the lime mortars had not been hardened by salt deposition. Indeed, in their natural state, these mortars would be too weak to permit mechanical stability of the thin septa (Fig. 5). 


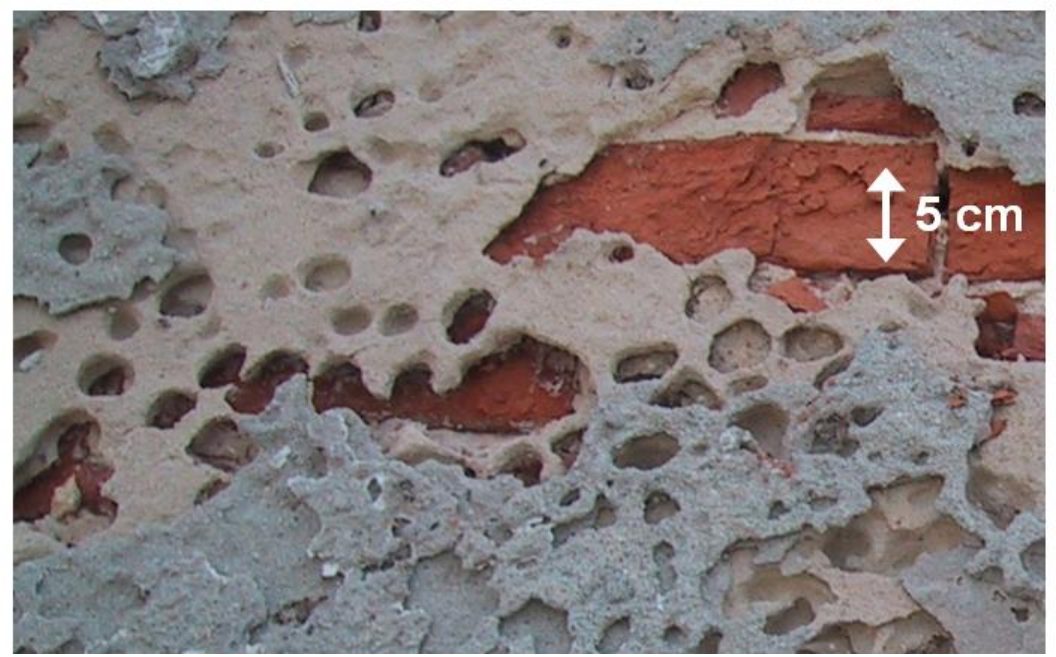

Fig. 5 - Alveolar decay of salt-hardened lime plaster with cement repairs, on an old building façade at a coastal area near Lisbon, Portugal

The topic of thermal expansion continued to sporadically emerge in the literature, but only at a conceptual level. Obika et al. (1992), for example, drew attention to the need for research on the topic while discussing salt damage features of bituminous road pavements. More recently, Lubelli et al. (2004) and Doehne \& Price (2010), among others, held that stress from differential thermal expansion is probably a relevant damage mechanism due to the higher expansion of salts like sodium chloride in relation to that of uncontaminated brick and calcite, respectively.

From the above, it is evident that there are contradictory views on the possible relevance of thermal expansion within salt decay, which highlights the need for further research on the topic. One of the main issues is that, as seen, experimental data is lacking. Another is that some authors address only microscopic damage (Fig. 1a) and others only macroscopic damage (Fig. 1b). So, even without considering the differences in materials and environmental conditions, their conclusions are not necessarily comparable.

To address these needs, we carried out experimental work on Ançã limestone and modelled its damage modes at the micro and macro scales, as presented in the following sections.

\section{Materials and Methods}

\section{Characteristics of Ançã limestone}

Ançã limestone, locally known as Pedra de Ançã, is a soft limestone from Cantanhede region, in the centre of Portugal. It is a very homogeneous white rock with fine-grained (aphanitic) texture and formed almost exclusively of calcite. Microscope observations have shown that this stone also includes dispersed fragments of thin-shell lamellibranch with variable dimensions, as well as some rare rolled quartz grains (Rodrigues 1998). Its main physical characteristics are reported in Table 1 and Fig. 6. 
Table 1 - Physical characteristics of Ançã limestone

\begin{tabular}{|c|c|c|c|}
\hline & $\begin{array}{l}\text { Measured } \\
\text { in this work }\end{array}$ & $\begin{array}{l}\text { Castro et al. } \\
(1975)\end{array}$ & $\begin{array}{l}\text { Ferreira Pinto } \\
(2002)\end{array}$ \\
\hline Density - $\rho\left(\mathrm{kg} \mathrm{m}^{-3}\right)$ & $1967^{(1)}$ & 1957 & 1972 \\
\hline Porosity - c (\%V) & $26^{(1)}$ & 28 & 27.2 \\
\hline Saturation coefficient - S (\%V) & $86.70^{(1)}$ & - & 87 \\
\hline Capillary water absorption coefficient - WAC $\left(\mathrm{kg} \mathrm{m}^{-2} \mathrm{~s}^{-1 / 2}\right)$ & $0.15^{(1)}$ & - & 0.18 \\
\hline Water vapour diffusion equivalent air layer thickness - Sd (m) & $0.40^{(1)}$ & - & - \\
\hline Uniaxial compressive strength - Rc (MPa) & - & 35.5 & 36.4 \\
\hline Tensile (flexural) strength - Rf (MPa) & - & - & $4.1-5.2$ \\
\hline Young's modulus - E (GPa) & - & 18.6 & - \\
\hline Poisson coefficient $-\nu(-)$ & - & 0.21 & - \\
\hline Linear compressibility - k $\left(\mathrm{GPa}^{-1}\right)$ & - & $0.031^{(2)}$ & - \\
\hline Coefficient of linear thermal expansion $-\alpha\left(10^{-6} /{ }^{\circ} \mathrm{C}\right)$ & $4.6^{(3)}$ & & 4.33 \\
\hline \multicolumn{4}{|l|}{ (1) measured according to RILEM procedures (RILEM 1980) } \\
\hline \multicolumn{4}{|l|}{ ulated from the experimental values of $E$} \\
\hline \multicolumn{4}{|l|}{ (3) average for the reference (salt free) specimens } \\
\hline
\end{tabular}

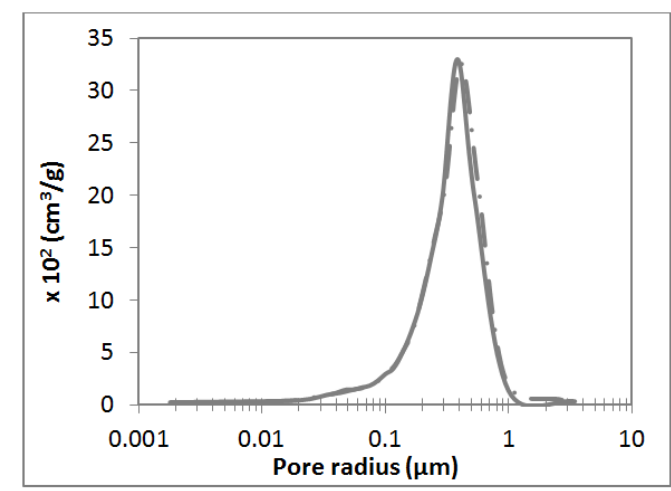

Fig. 6 - Pore size distribution of Ançã limestone; determined according to standard ASTM D4404-84 (ASTM 2004)

\section{Thermal expansion measurements}

The linear thermal expansion coefficient was measured using stone specimens of $24 \mathrm{~mm} \times 24 \mathrm{~mm} \times 100$ $\mathrm{mm}$. These specimens were contaminated by keeping them in total immersion during three days in saturated solutions of sodium chloride $(\mathrm{NaCl})$, sodium sulphate $\left(\mathrm{Na}_{2} \mathrm{SO}_{4}\right)$ or sodium nitrate $\left(\mathrm{NaNO}_{3}\right)$. Two specimens were typically used for each experimental condition.

The saturated solutions had been previously prepared by adding anhydrous salt to distilled water at $60^{\circ} \mathrm{C}$, stirring constantly in a magnetic stirrer, until it was clear that no more salt could be dissolved. They were then let cool to room temperature in a conditioned room at $20^{\circ} \mathrm{C}$ during an overnight, and afterwards filtered to remove the excess crystallized salt. According to Lurie (1975), at $20^{\circ} \mathrm{C}$, saturated solutions contain $36 \mathrm{~g}$ of sodium chloride, $19.4 \mathrm{~g}$ of sodium sulphate or $88 \mathrm{~g}$ of sodium nitrate, respectively, per $100 \mathrm{~g}$ of water. These values correspond to the amount of anhydrous salt. 
After the immersion period, the specimens were oven-dried at $105^{\circ} \mathrm{C}$ until constant mass. During the drying period, efflorescence arose for $\mathrm{NaCl}$ and $\mathrm{NaNO}_{3}$ (Fig. 7). $\mathrm{Na}_{2} \mathrm{SO}_{4}$ did not give rise to efflorescence.

Efflorescence had to be removed before the thermal expansion measurements. The amount of salt that remained in the stone pores, as subflorescence, is a function of the salt solubility because this determines how much salt the solution contains and, hence, the salt content of the specimens at the end of the immersion period. But this amount is also affected by the dynamics of drying: the slower the drying the longer the drying front stays at the surface of the material and, therefore, the higher the amount of salt that crystallizes as efflorescence rather than as subflorescence (Brito and Diaz Gonçalves 2013).

The salt content (SC) of each specimen was calculated through Eq. 10:

$$
S C=100 \frac{\text { Msalt }- \text { Mdry }}{\text { Mdry }}[\%]
$$

in which Mdry $(\mathrm{g})$ is the dry mass of the specimen before salt contamination and Msalt $(\mathrm{g})$ its dry mass after removing the efflorescence.

Two sets of repeat thermal expansion measurements on different groups of specimens, T1 and T2, were performed at different moments in time, as described in Table 2.

Two types of reference specimens were used:

(i) Control specimens in which pure water was used instead of salt solution, to represent the situation of $0 \%$ salt content. Both sets of tests included measurements on this type of reference specimens.

(ii) Blank specimens not subjected to wetting. These served to evaluate the occurrence of changes simply due to hydric expansion (which was not the case) and were used in set T2.

The reference specimens were oven dried at $105^{\circ} \mathrm{C}$, similarly to the salt contaminated specimens. After drying, all the specimens were stored in a desiccator cabinet.
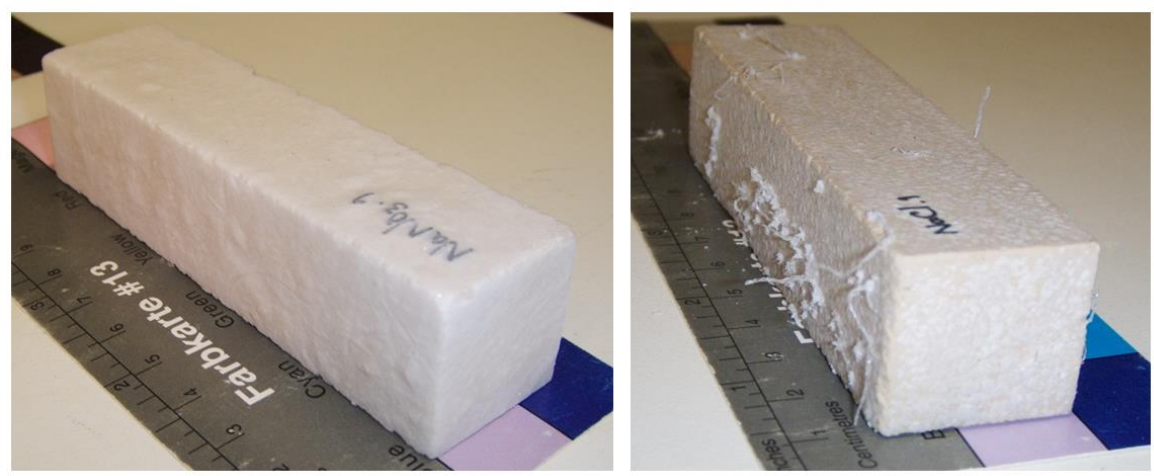

Fig. 7 - Efflorescence of $\mathrm{NaNO}_{3}$ (left) and $\mathrm{NaCl}$ (right) after oven-drying at $105^{\circ} \mathrm{C}$

Table 2 - Contamination conditions of the test specimens used in either set of thermal expansion measurements

\begin{tabular}{|c|c|c|c|c|c|}
\hline \multirow{3}{*}{$\begin{array}{l}\text { Set of } \\
\text { tests }\end{array}$} & \multirow{2}{*}{\multicolumn{3}{|c|}{$\begin{array}{l}\text { After immersion in saturated salt } \\
\text { solution and subsequent drying }\end{array}$}} & \multicolumn{2}{|c|}{ Reference, salt free specimens } \\
\hline & & & & \multirow{2}{*}{$\begin{array}{l}\text { Control } \\
\text { specimens } \\
\text { (pure water) }\end{array}$} & \multirow{2}{*}{$\begin{array}{l}\text { Blank } \\
\text { specimens } \\
\text { (no wetting) }\end{array}$} \\
\hline & $\mathrm{NaCl}$ & $\mathrm{Na}_{2} \mathrm{SO}_{4}$ & $\mathrm{NaNO}_{3}$ & & \\
\hline T1 & $\mathrm{x}$ & $x$ & $x$ & $\mathrm{x}$ & - \\
\hline T2 & $x$ & $x$ & - & $x$ & $x$ \\
\hline
\end{tabular}


The linear thermal expansion of Ançã limestone was measured using a Theta Dilamatic $1200 \mathrm{C}$ dilatometer (Fig. 8). This equipment is programmable and has resolution of $1 \mu \mathrm{m}$ in length measurements and of $0.1^{\circ} \mathrm{C}$ in surface temperature measurements. During the tests, nominal temperature varied between $20^{\circ} \mathrm{C}$ and $85^{\circ} \mathrm{C}$, as depicted in Fig. 9. The temperature program consisted of 60 -minute periods at constant temperature of $35^{\circ} \mathrm{C}, 45^{\circ} \mathrm{C}, 55^{\circ} \mathrm{C}, 70^{\circ} \mathrm{C}$ or $85^{\circ} \mathrm{C}$, between each of which the temperature increased at a rate of $5^{\circ} \mathrm{C} / \mathrm{min}$. The dilatometer was installed in a room with temperature of around $20^{\circ} \mathrm{C}$ and relative humidity $(\mathrm{RH})$ of $50 \%$ to $70 \%$.

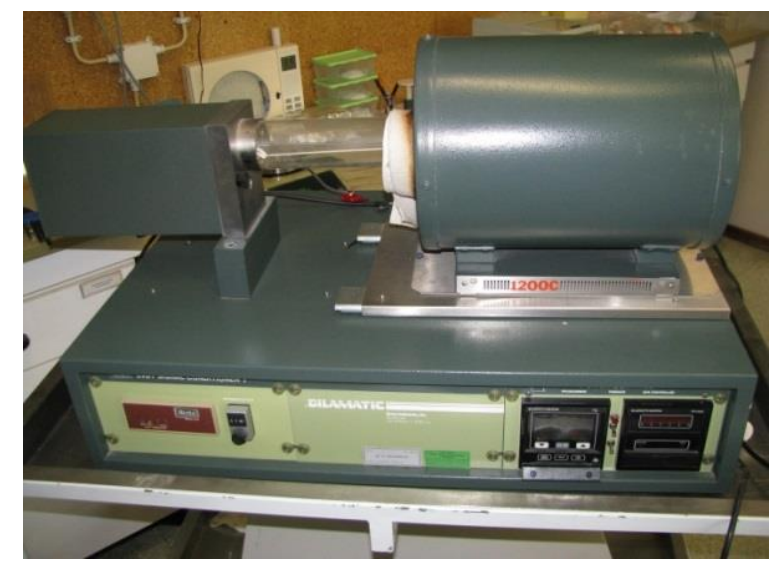

Fig. 8 - Dilatometer

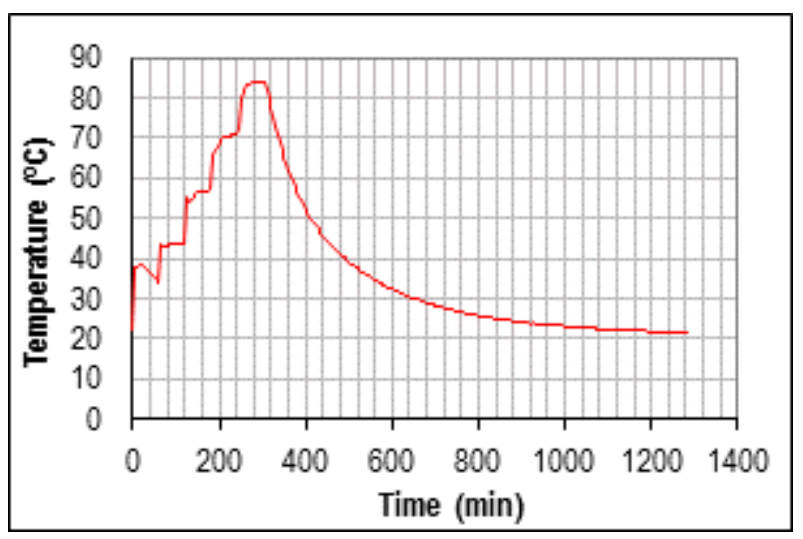

Fig. 9 -Example of the temperature program (test T2)

The method to determine the coefficient of linear thermal expansion is as follows. The increase in length $(\Delta \mathrm{L})$ in relation to the initial length of the specimen $\left(\mathrm{L}_{0}\right)$ is measured at the end of each period at constant temperature. Afterwards, $\Delta \mathrm{L} / \mathrm{L}_{0}$ is plotted as a function of temperature $\mathrm{T}$. The coefficient of linear thermal expansion $\alpha\left({ }^{\circ} \mathrm{C}^{-1}\right)$ is then given by the slope of the least squares regression line, as expressed by Eq. 11 (note that Eq. 11 is equivalent to Eq. 1).

$\alpha=\frac{\Delta L}{L_{0} \times \Delta T}$

in which $\Delta L(m)$ is the increase in length in relation to the initial length of the specimen $L_{0}(m)$ and $T$ the temperature $\left({ }^{\circ} \mathrm{C}\right)$.

This method holds well when the variation of $\Delta \mathrm{L} / \mathrm{L}_{0}$ with $\mathrm{T}$ is approximately linear, i.e. if $\alpha$ is approximately constant, which was always the case in this work. This means that $\alpha$ is representative of the behaviour of the material for any temperature range between $20^{\circ} \mathrm{C}$ and $85^{\circ} \mathrm{C}$. 
The crystal phases of sodium chloride, sodium sulphate and sodium nitrate expected to be present in the material at the end of drying at $105^{\circ} \mathrm{C}$ and further cooling to $20^{\circ} \mathrm{C}$ are halite $(\mathrm{NaCl})$, thenardite $\left(\mathrm{Na}_{2} \mathrm{SO}_{4}\right)$ and nitratite $\left(\mathrm{NaNO}_{3}\right)$, respectively. These equilibrium crystal phases are also the ones expected to exist subsequently because deliquescence might hardly have occurred during the thermal expansion measurements. Indeed, the $\mathrm{RH}$ of the air in the dilatometer at the beginning of the measurements was, at the maximum, of $70 \%$ (the maximum $\mathrm{RH}$ registered in the room during the tests), which is below the deliquescence $\mathrm{RH}$ of the three crystalline phases at $20^{\circ} \mathrm{C}$. The temperature was then raised to $100^{\circ} \mathrm{C}$ and, therefore, the $\mathrm{RH}$ of the air in the dilatometer decreased even further (because hot air is able to contain more water vapour) until, at $100^{\circ} \mathrm{C}$, it was less than $10 \%$. No deliquescence of the salts could therefore have taken place because: the deliquescence $\mathrm{RH}$ of halite does not vary significantly with temperature (Schwarz a, 2014); that of thenardite increases slightly with the increase in temperature (Schwarz et al., 2014); that of nitratite decreases with temperature, but not as much as the air $\mathrm{RH}$ in the dilatometer did (Schwarz b, 2014).

\section{Results of the thermal expansion measurements}

The experimental results are depicted in Fig. 10, which shows how the coefficient of linear thermal expansion of the Ançã varies with its salt content. All the values we used to draw this graph are available in Tables A. 1 to A.5, in the Appendix.

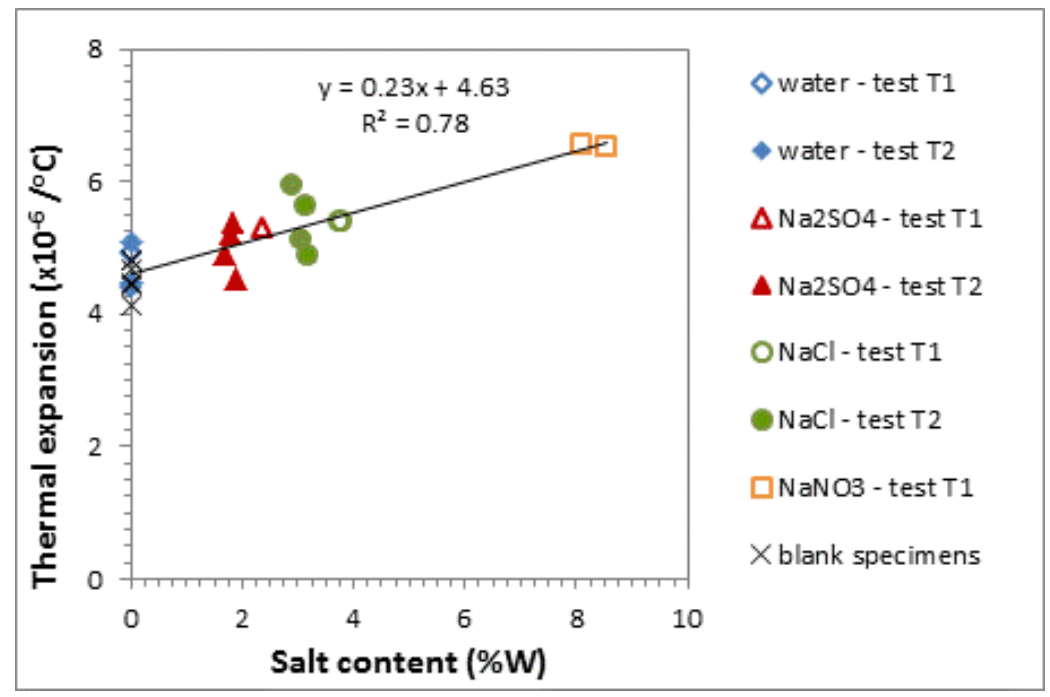

Fig. 10 - Coefficient of linear thermal expansion of Ançã limestone as a function of its salt content (measured in this work)

For the uncontaminated stone, the coefficient of linear thermal expansion has value similar to that reported by Ferreira Pinto (2002) which can be found in Table 1. However, for the salt-contaminated stone, much higher values were systematically obtained, as seen in Fig. 10. For example, a stone with $5 \%$ salt content would expand $25 \%$ more than a stone free of salt. This suggests that temperature changes can give rise to significant shear stress at the interface between salt contaminated and uncontaminated stone layers, eventually causing the type of macroscopic damage illustrated in Fig. $1 \mathrm{~b}$.

The trendline in Fig. 10 is a first order approximation and suggests that the coefficient of thermal expansion of the Ançã increases approximately linearly with its salt content, irrespective of the type of salt. That means that the thermal expansion of the stone will depend more on the amount of salt it contains than on the nature of that salt. 
This low relevance of the type of salt suggests that the linear thermal expansion of the three salts is similar. But that is not straightforward to verify because the thermal expansion of salt crystals depends on the orientation with respect to the crystallographic axis, and is not necessarily isotropic. Indeed, only minerals with a cubic crystal structure have isotropic thermal expansion. For that reason, the linear thermal expansion of halite which is cubic is isotropic, contrary to that of thenardite and nitratite. Thenardite is orthorhombic and, thus, has three coefficients of linear thermal expansion (Arbeck 2012). Nitratite is hexagonal and, therefore, has two (Skinner 1966). However, in a porous network, crystals are randomly oriented and, so, we should consider not the axial coefficients, but their average.

Table 3 - Average linear thermal expansion of the uncontaminated limestone and individual salts

\begin{tabular}{|c|c|c|c|c|c|}
\hline \multirow[b]{3}{*}{ Substance } & \multicolumn{5}{|c|}{ Coefficient of linear thermal expansion $\left(\times 10^{-6} /{ }^{\circ} \mathrm{C}\right)$} \\
\hline & \multirow[b]{2}{*}{ Measured in this work } & \multicolumn{4}{|c|}{ Given in the literature } \\
\hline & & $\begin{array}{l}\text { Robertson } \\
\text { et al. (1958) }\end{array}$ & $\begin{array}{c}\text { Skinner } \\
(1966)\end{array}$ & Ibrahim (1986) & $\begin{array}{c}\text { Espinoza- } \\
\text { Marzal and } \\
\text { Scherer (2009) }\end{array}$ \\
\hline Limestone & $\begin{array}{c}4.6^{*} \\
(S t d=0.3)\end{array}$ & - & 4 to 12 & - & - \\
\hline Halite (NaCl) & - & 32 & $32.1^{* *}$ & - & - \\
\hline Thenardite $\left(\mathrm{Na}_{2} \mathrm{SO}_{4}\right)$ & - & - & - & - & 28.8 \\
\hline Nitratite $\left(\mathrm{NaNO}_{3}\right)$ & - & - & $35.9^{* *}$ & 28.0 & - \\
\hline
\end{tabular}

The values of the average linear thermal expansion coefficient given by different authors for the three individual salts are depicted in Table 3. These values show that, in fact, the thermal expansion of the three salts is not very different, especially when contrasted to the thermal expansion of the limestone (also given in the table) and to the significant dispersion of the experimental values (Figure 10). Hence, they support the above stated hypothesis that this is the reason why the thermal expansion of the stone is mostly independent of the type of salt.

The dispersion of experimental values may be related to: (i) the test method itself; (ii) material heterogeneity; (iii) heterogeneous salt distribution in the material. This last hypothesis is not probably as relevant as the first two, since the reference specimens also show dispersion. This may be addressed in further research, for example, by using broader ranges of salt content. That can be achieved, for example, by manipulating the drying conditions because the lower the evaporation rate the more salt will crystallize as efflorescence and vice-versa.

The main observation to be made out of Table 3, however, is that the thermal expansion of any of the salts is in fact much higher than that of Ançã limestone: the thermal expansion of the salts is $610 \%$ to $783 \%$ times greater than that of the stone. This huge difference justifies the need to seriously consider thermal expansion as a possible decay mechanism also at the microscopic scale (Fig. 1a). 


\section{Predicting the thermal expansion coefficient as a function of salt content}

\section{Semi-empirical linear model}

It would be useful to have a mathematical model to predict the thermal expansion coefficient of porous building materials as a function of their salt content because, as seen, measuring this coefficient experimentally is not straightforward.

Deriving an equation for this type of model is greatly simplified if we assume the linear trend suggested by our experimental data (Fig. 10). In such case, we need only two points to define the equation. These points can be those corresponding to the thermal expansion coefficients of the uncontaminated material $(0 \%$ salt content) and pure salt (100\% salt content). In the literature, there are values of the thermal expansion coefficient available for many types of stone and salts, and using them would remove the need for experimental work altogether. This would be particularly valuable for the salts because measuring the thermal expansion of individual crystals is a meticulous job that requires sophisticated equipment (Krishnan et al. 1979).

Eq. 12 gives the general form of this type of semi-empirical linear model.

$$
\alpha^{*}=\frac{\alpha_{c r}-\alpha_{s t}}{100} \cdot M S C+\alpha_{s t}
$$

in which $\alpha^{*}$ is the coefficient of linear thermal expansion of the salt contaminated stone $\left(/{ }^{\circ} \mathrm{C}\right), \alpha_{c r}$ the thermal expansion coefficient of the salt crystal (/으), $\alpha_{s t}$ the thermal expansion coefficient of the stone (/으) and $M S C$ the salt content (\%W).

Table 4 presents the equations obtained for the present case of Ançã stone with sodium chloride, sulphate and nitrate, respectively. They were derived from Eq. 12, using the values in (Table 3). As seen, there is one equation for each type of salt, except for $\mathrm{NaNO}_{3}$ for which there are two. These two equations correspond to the values of the thermal expansion of nitratite given by Skinner (1966) and Ibrahim (1986), respectively, which are quite different.

Table 4 - Equations of the theoretical model for the thermal expansion of the salt loaded stone

\begin{tabular}{llll} 
& $\begin{array}{l}\text { Value considered } \\
\text { for } 0 \% \text { of salt }\end{array}$ & $\begin{array}{l}\text { Value considered } \\
\text { for } 100 \% \text { of salt }\end{array}$ & $\begin{array}{l}\text { Coefficient of linear thermal } \\
\text { expansion }\left(\times 10^{-6} / 0 \mathrm{C}\right)\end{array}$ \\
\hline Halite $(\mathrm{NaCl})$ & $32.100^{(2)}$ & $\alpha^{*}=0.275^{\star} \mathrm{MSC}+4.600$ \\
Thenardite $\left(\mathrm{Na}_{2} \mathrm{SO}_{4}\right)$ & $4.600^{(1)}$ & $28.800^{(3)}$ & $\alpha^{*}=0.242^{*} \mathrm{MSC}+4.600$ \\
Nitratite $\left(\mathrm{NaNO}_{3}\right)$ & & $35.900^{(2)}$ & $\alpha^{*}=0.313^{*} \mathrm{MSC}+4.600$ \\
& & $28.000^{(4)}$ & $\alpha^{*}=0.234^{*} \mathrm{MSC}+4.600$
\end{tabular}

\footnotetext{
(1) Average value measured in this work for the uncontaminated limestone

(2) Skinner (1966)

(3) Espinoza-Marzal and Scherer (2009)

(4) Ibrahim (1986)
}

The goodness of fit between the semi-empirical linear model in Table 4 and our experimental values (Fig. 10) can be evaluated through graphs a) and b) in Fig. 11. These graphs were obtained by plotting the values of $\alpha^{*}$ calculated through the semi-empirical model against either the individual experimental values (graph a) or those calculated through the experimental regression equation in Fig. 10 (graph b). For 
$\mathrm{NaNO}_{3}$, the models were run twice, using the thermal expansion values reported by Skinner (1966) and Ibrahim (1986), respectively. The dashed lines are the reference for perfect fit.
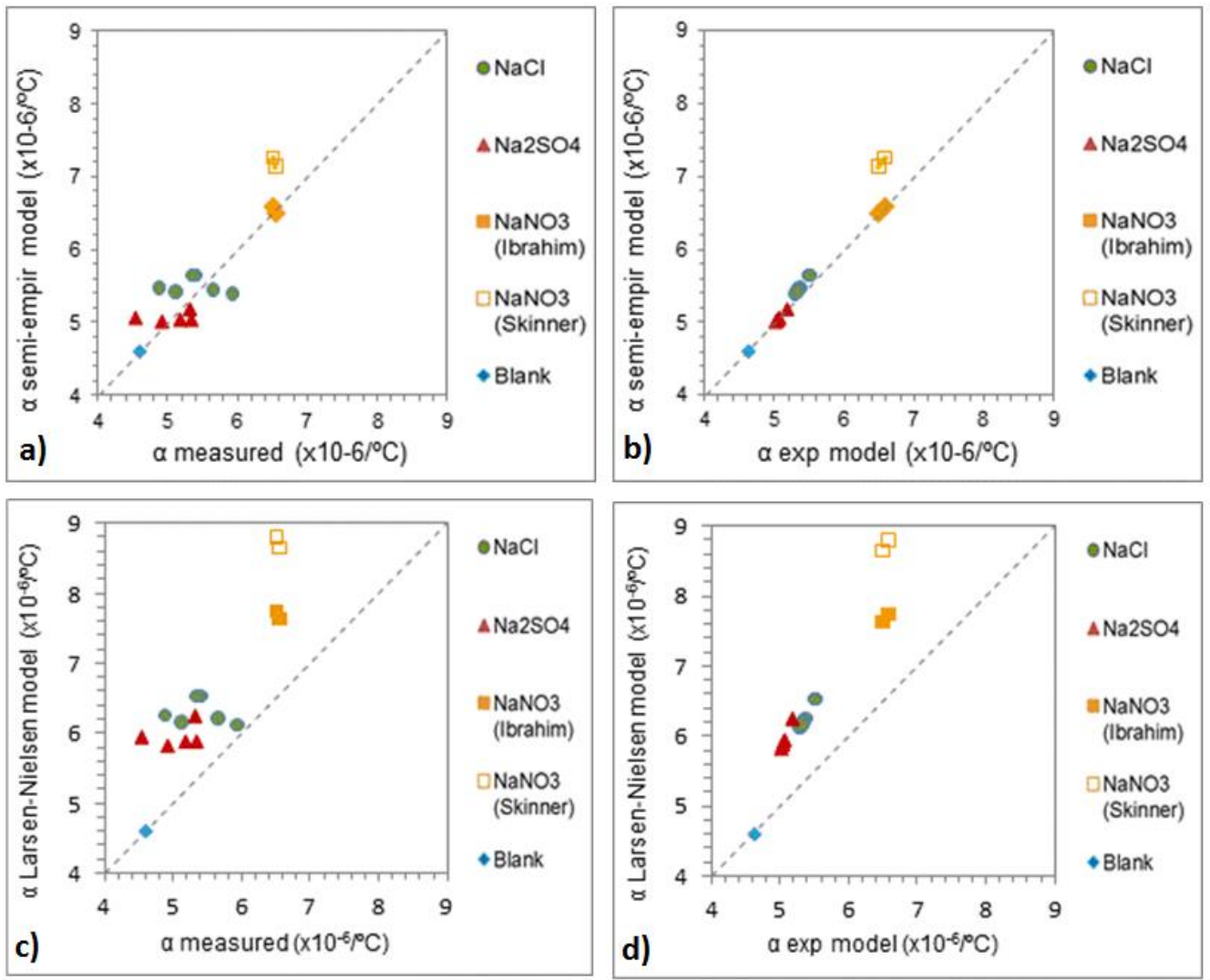

Fig. 11 - Goodness of fit between models and experimental data. Above: comparison of the semi-empirical linear to either the individual experimental measurements (graph a) or the experimental regression model in Fig 10 (graph b). Below: comparison of Larsen and Nielsen's model to either the individual experimental measurements (graph $c$ ) or the experimental regression model in Fig 10 (graph $d$ ).

As seen in Fig. 11, the fit is very good for $\mathrm{NaCl}$ and $\mathrm{Na}_{2} \mathrm{SO}_{4}$. However, for $\mathrm{NaNO}_{3}$ the goodness-of-fit depends on the author: it is excellent for the values of Ibrahim (1986) but not that good for those of Skinner (1966). This confirms that although the thermal expansion of the Ançã can overall be assumed to vary linearly with its salt content, the accuracy of this assumption can vary. Indeed, the values given by different authors for the thermal expansion of salts can differ, which adds uncertainty to the analysis. This problem could be overcome in the future by putting forward a database (or extending existing ones) with reliable and consistent values for the thermal expansion of salts and materials relevant for cultural heritage.

\section{Larsen and Nielsen's model}

Larsen and Nielsen (1990) proposed a different kind of model to predict the thermal expansion coefficient of brick as a function of its $\mathrm{NaCl}$ content. The model is a sphere of material with a central spherical pore filled with salt and its analytical expression is given in Eqs. 4 to 9. The properties of the porous material and salt can be adjusted by changing the values of the elastic and mechanical constants in the model. Therefore, although Larsen and Nielsen used it for brick and $\mathrm{NaCl}$, the model could be applicable to other porous materials and salts. As this was the only model of the kind proposed until now, we decided to verify it against the experimental results obtained in this work for Ançã stone with sodium chloride, sulphate and nitrate.

Note that Larsen and Nielsen's model describes the relationship between the thermal expansion coefficient and salt content as a second order (parabolic) curve (Fig. 12). In contrast, our experimental data was 
described by a linear relationship (Fig. 10). However, this is a first-order approximation and, in fact, the data could also fit a second-order curve like the one in Fig. 12. This suggests that the linearity of our experimental results (Fig. 10), and also of those obtained by Larsen and Nielsen's (1990), could be valid only as a local approximation.

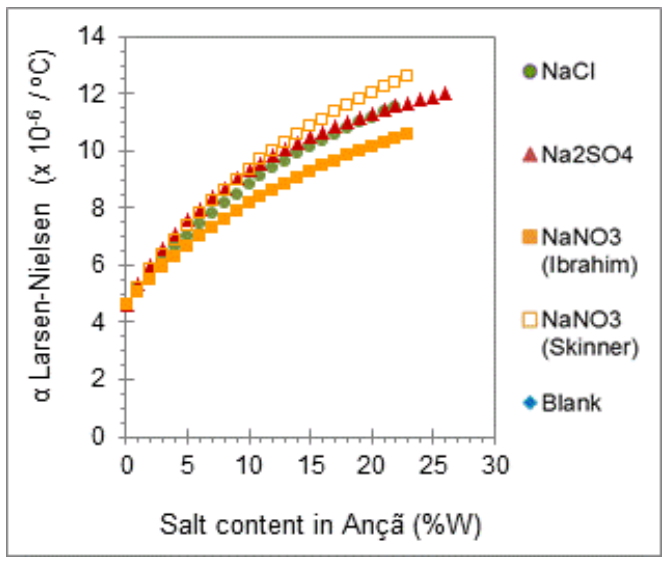

Fig. 12 - Thermal expansion coefficient of Ançã stone as a function salt content according to the model of Larsen and Nielsen.

To verify Larsen and Nielsen's model, we used the values given in Table 1 for the porosity $(c=0.26)$, dry density $\left(\rho_{b}=1967 \mathrm{~kg} / \mathrm{m}^{3}\right)$ and Young's modulus $\left(E_{b}=18.6 \mathrm{GPa}\right)$ of the stone. For the dry density $\left(\rho_{s}\right)$ and Young's modulus $\left(E_{s}\right)$ of the salts we used values found in the literature, which are depicted in Table 5. The thermal expansion coefficients of the uncontaminated stone and pure salts are those given in Table 3. For the thermal expansion coefficient of the salt contaminated stone $\alpha \star$ and corresponding salt content MSC we used our experimental data (Fig. 10 and Appendix).

Table 5 - Density and elasticity moduli of the salts

\begin{tabular}{lll}
\cline { 2 - 3 } & $\begin{array}{l}\text { Density } \\
\rho_{\mathrm{s}}\left(\mathrm{kg} / \mathrm{m}^{3}\right)\end{array}$ & $\begin{array}{l}\text { Young's } \\
\text { modulus } \\
\mathrm{E}_{\mathrm{s}}(\mathrm{GPa})\end{array}$ \\
\hline Halite $(\mathrm{NaCl})$ & $2163^{(1)}$ & $43.4^{(4)}$ \\
Thenardite $\left(\mathrm{Na}_{2} \mathrm{SO}_{4}\right)$ & $2689^{(2)}$ & $84.3^{(5)}$ \\
Nitratite $\left(\mathrm{NaNO}_{3}\right)$ & $2260^{(3)}$ & $44.7^{(6)}$
\end{tabular}

(1) Schwarz (a)

(2) Schwarz et al. (-)

(3) Schwarz (b)

(4) Birch et al. (1942)

(5) average of the moduli for axial compression given by Allan et al. (1993)

(6) Bass (1995)

The goodness of fit of Larsen and Nielsen's model to our experimental data can be assessed through graphs c) and d) in Fig. 11. As seen, in neither of these graphs the fit is good, with the model significantly overestimating the coefficient of thermal expansion of the salt contaminated stone. This overestimation may to some extent be due, for example, to an heterogeneous distribution of salt in the specimens. But it may also be due to the model itself. For example, the model considers an isolated, spherical pore, filled with salt. However, the pore structure of porous building materials is composed of interconnected pores of different size and often irregular shapes. Furthermore, as known today, salt does not completely fill the pores. These features, especially pore shape, may reproduce better the brick tested by Larsen and Nielsen 
(1990) than our stone, which could explain which they reached a good agreement with their experimental data whereas we did not.

\section{Will thermal expansion cause damage to the salt contaminated Ançã? \\ Microscopic-level damage}

To answer the central question of whether the thermal expansion of salts can cause damage to Ançã stone, we will express, first graphically and then analytically, the conceptual models in Fig. 1.

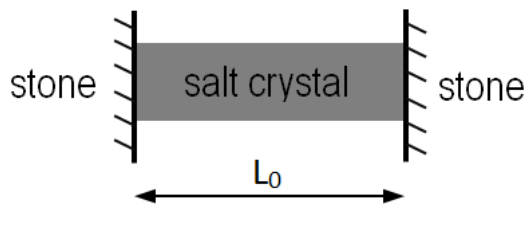

a) Microscopic level

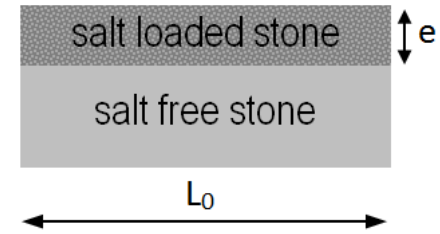

b) Macroscopic level

Fig. 13 - Thermal expansion damage systems

In this section we will discuss the possibility that damage takes place at the microscopic level, i.e., that the expansion of individual salt crystals in the pores disrupts the stone, as shown in Fig. 1a. This microscopic damage mechanism is graphically expressed by the simplified system in Fig. 13a. The system is composed by an idealized crystal of length $L_{0}(m)$, in which the extremities are in direct contact with the internal walls of a stone pore. Linear elastic behaviour is assumed.

We will consider conservatively that thermal expansion causes an increase in pore size $\left.\Delta\right|_{\text {st }}{ }^{\top}(m)$, as given by Eq. 1. However, as will be seen later, this has no significant influence on the final result.

$\Delta l_{s t}^{T}=\alpha_{s t} \times L_{0} \times \Delta T$

in which $\alpha_{s t}\left(/{ }^{\circ} \mathrm{C}\right)$ is the coefficient of linear thermal expansion of the stone and $\Delta T\left({ }^{\circ} \mathrm{C}\right)$ the temperature range.

The thermal expansion of the salt crystal $\Delta \mathrm{l}_{\mathrm{cr}}{ }^{\top}(\mathrm{m})$, if it were free, would be given by:

$\Delta l_{c r}^{T}=\alpha_{c r} \times L_{0} \times \Delta T$

in which $\alpha_{c r}(/ 0 \mathrm{C})$ is the coefficient of linear thermal expansion of the salt.

But the expansion of the crystal in reality is constrained by the pore walls. To fit the dimension of the pore the crystal has to be compressed by $\Delta \mathrm{l}_{\mathrm{cr}} \mathrm{P}(\mathrm{m})$, as expressed by Eq. 16.

$\Delta l_{c r}{ }^{P}=\Delta l_{c r}{ }^{T}-\Delta l_{s t}{ }^{T}$

Assuming that the stone suffers no relevant deformation under the pressure exerted by the salt crystal on the pore walls, the crystal becomes subjected to a pressure $P(\mathrm{~Pa})$ which, as it comes from Eq. 2, is given by Eq. 16.

$\Delta l_{c r}{ }^{P}=k_{c r} \times\left(L_{0}+\Delta l_{c r}{ }^{T}\right) \times P$ 
in which $k_{c r}(/ \mathrm{Pa})$ is the linear compressibility of the salt crystal.

Replacing Eqs. 13, 14 and 16 in Eq. 15, we obtain Eq. 17. This equation gives the temperature range to which we need to subject the system, so that the salt crystal imposes a pressure $P$ on the stone. The term $k_{c r} \cdot \alpha_{c r}$ is so small that it can be considered zero, which is the same than disregarding the increase in pore size $\Delta \mathrm{l}_{\mathrm{st}}^{\top}$ given in Eq. 13.

$$
\Delta T=\frac{k_{c r}+k_{c r} \alpha_{c r}}{\alpha_{c r}-\alpha_{s t}} P \approx \frac{k_{c r}}{\alpha_{c r}-\alpha_{s t}} P
$$

Eq. 17 can be used to calculate the minimum temperature range $\Delta T^{\text {min }}$ at which the compressive strength of the Ançã will be reached. For this, we replace $P$ by the value of that compressive strength, which we will assume is of $35.5 \mathrm{MPa}$ (Table 1). The compressibility of salt crystals vary with orientation, except in the case of halite which is isotropic (Table 6). Conservatively, we will use the smaller values, i.e., $\mathrm{k}_{\mathrm{cr}}{ }^{\mathrm{NaCl}}=23 \times 10^{-}$ ${ }^{12} / \mathrm{Pa}, \mathrm{k}_{\mathrm{cr}}{ }^{\mathrm{Na} 2 \mathrm{SO} 4}=10 \times 10^{-12} / \mathrm{Pa}$ and $\mathrm{k}_{\mathrm{cr}}{ }^{\mathrm{NaNO}}=18 \times 10^{-12} / \mathrm{Pa}$. The thermal expansion coefficient of the salts also depends on the orientation and, conservatively, we should use the maximum axial value. However, reliable axial values could not be found for thenardite and nitratite and, so, we will use the average values reported in Table 3, $\alpha_{\mathrm{cr}}{ }^{\mathrm{NaCl}}=32 \times 10^{-6} /{ }^{\circ} \mathrm{C}, \alpha_{\mathrm{cr}}{ }^{\mathrm{Na} 2 \mathrm{SO} 4}=28.8 \times 10^{-6} /{ }^{\circ} \mathrm{C}$ and $\alpha_{\mathrm{cr}}{ }^{\mathrm{NaNO} 3}=35.9 \times 10^{-6} /{ }^{\circ} \mathrm{C}$. Finally, the linear thermal expansion coefficient of the Ançã, measured in this work and given in Table 3, is $\alpha_{\mathrm{st}}=4.6 \times 10^{-6} /{ }^{\circ} \mathrm{C}$.

Table 6 - Elastic compliance constants of single crystals for axial compression $\left(\times 10^{-12} / \mathrm{Pa}\right)$

\begin{tabular}{|c|c|c|c|}
\hline & $\mathrm{S}_{11}$ & $\mathrm{~S}_{22}$ & $\mathrm{~S}_{33}$ \\
\hline Halite $(\mathrm{NaCl}){ }^{*}$ & 23 & - & - \\
\hline Thenardite $\left(\mathrm{Na}_{2} \mathrm{SO}_{4}\right)$ ** & 15 & 10 & 12 \\
\hline Nitratite $\left(\mathrm{NaNO}_{3}\right)^{*}$ & 18 & - & 29 \\
\hline
\end{tabular}

\footnotetext{
* from Bass (1995)

** from Allan et al. (1993)
}

From the above calculations, we estimate that the compressive strength of the Ançã will be reached, in at least some pores, if the system is subjected to the following temperature ranges: $\Delta T^{\mathrm{min}}{ }_{\mathrm{NaCl}} \approx 30^{\circ} \mathrm{C}$, $\Delta \mathrm{T}^{\mathrm{min}} \mathrm{Na}_{2 \mathrm{SO} 4} \approx 15^{\circ} \mathrm{C}$ and $\Delta \mathrm{T}^{\mathrm{min}} \mathrm{NaNO}_{3} \approx 20^{\circ} \mathrm{C}$. Temperature variations of these or higher magnitudes can be reached on facades exposed to sunlight, namely in southern Europe countries like Portugal, both seasonally and daily during summer (de la Rosa et al. 2013, RCCTE 2006, Diaz Gonçalves et al. 2015).

Note that we are assuming that the crystals have higher compressive strength than the stone. Otherwise the crystal would break before damaging the stone. This assumption is not easy to verify due to a lack of reliable values for the mechanical strength of salt crystals in the literature. However, Johannessen et al. (1982), for example, say that sodium chloride in the form of rock salt or individual halite crystals has an ultimate strength of $26 \mathrm{MPa}$ to $38 \mathrm{MPa}$. As the crystals should be in the higher end of this interval, it is likely that their strength is higher than that of the Ançã (Table 1). As to the other two salts, the uniaxial compressive strength of thenardite is larger than that of halite (Liang et al. 2010) and we will assume that the same happens to nitratite.

Note also that our reasoning is highly conservative. Indeed, it is probable that, similar to damage caused by salt crystal growth (Derluyn 2012), the resistance of porous materials to this type of internal pressure is determined by their tensile rather than by their compressive strength. And the tensile strength of porous 
building materials is much lower than their compressive strength. That of the Ançã, for example, is only c. 5 MPa (Table 1), i.e., seven times smaller than its compressive strength.

We do not think it would have been wise to consider here only the tensile strength because we are working with conservative assumptions. But the tensile strength can be seen as a lower threshold, so it is interesting to see what happens when we use it instead of compressive strength.

If we repeat the above calculations for a strength value of $5 \mathrm{MPa}$, we conclude that the mechanical strength of the Ançã can be reached at extremely low temperature ranges, $\Delta T^{\mathrm{min}}{ }_{\mathrm{NaC}} \approx 4^{\circ} \mathrm{C}, \Delta \mathrm{T}^{\mathrm{min}}{ }_{\mathrm{Na} 2 \mathrm{SO} 4 \approx 2^{\circ} \mathrm{C}}$ and $\Delta \mathrm{T}^{\mathrm{min}}{ }_{\mathrm{NaNO}} \approx 3^{\circ} \mathrm{C}$, which can easily be reached in any European climate and every season.

We have therefore to conclude that thermal expansion can be an effective decay mechanism at the microscopic level for Ançã stone with the three types of salt under study. However, the calculations and discussion above shows also how important it is that reliable databases start being created or existing ones extended to include reliable and consistent data on the mechanical properties of salts relevant to cultural heritage.

\section{Macroscopic-level damage}

The macroscopic level damage mode is schematized in Fig. 13b. This figure represents a system composed by a piece of Ançã stone in which only the surface layer is contaminated with salt. As before, the system is assumed to have linear elastic behaviour and is subjected to a rise in temperature $\Delta T$.

If the two layers were free to move independently, the surface layer would expand more than the bulk, as follows from our experimental results which show that the thermal expansion coefficient of the Ançã increases with salt content (Fig. 10). But since the two layers are united, the rise in temperature induces shear stress at their interface. If this stress exceeds the shear strength of the stone, the surface layer will detach.

We will assume that the thermal expansion of the bulk stone is zero. This assumption is conservative on the side of maximizing the occurrence of damage. It is a reasonable assumption, because, due to the low thermal conductivity of stone materials, temperature variations will affect mostly the outer layer of stone.

The expansion $\left.\Delta\right|^{*^{\top}}(\mathrm{m})$ of the salt contaminated layer, if it were free to move independently, is given by Eq.18.

$\Delta l * T=\alpha * \times L_{0} \times \Delta T$

in which $\alpha^{*}(/ \circ \mathrm{C})$ is the thermal expansion coefficient of the salt contaminated stone.

This surface layer, however, cannot expand because it is attached to the bulk stone. Therefore, it will suffer compression, as described by Eq. 19.

$\Delta l *^{P}=k * \times\left(L_{0}+\Delta l *^{T}\right) \times P \approx k * \times L_{0} \times P$

in which $P(\mathrm{~Pa})$ is the compressive stress, $k^{*}\left(\mathrm{~Pa}^{-1}\right)$ the linear compressibility of the contaminated stone and $\Delta I^{* P}(\mathrm{~m})$ the contraction of the surface layer. This equation can be simplified as shown because the influence of $\left.\Delta\right|^{{ }^{\top}}$ on $L_{0}$ is so small that it can be considered zero. 
We will consider that the tensile stress transmitted by the surface layer to the bulk stone is zero, which seems reasonable given that the detached layers are usually much thinner (Fig. 3). Therefore, the following equilibrium equation applies:

$\Delta l *^{T}-\Delta l *^{P}=0$

We will assume, as an approximation, that the linear compressibility of the contaminated stone is equal to that of the uncontaminated stone, i.e. that $k^{*}=k_{s t}$. Thus, replacing Equations 18 and 19 in Equation 20, we obtain the expression for the compression stress in the contaminated layer, which is given by Eq. 21 .

$$
P=\frac{\alpha^{*}}{k_{S T}} \Delta T
$$

We can also derive the equation for the shear stress $S(\mathrm{~Pa})$ at the interface between the two layers. This depends on $P$ but also on $L_{0}(\mathrm{~m})$ and on the thickness $e(\mathrm{~m})$ of the salt contaminated layer, as shown in Eq. 22.

$S=\frac{e}{L_{0}} P$

Replacing Eq. 21 in Eq. 22, using the value given in Table 1 for the linear compressibility of the Ançã $\left(\mathrm{k}_{\mathrm{ST}}=0.031 \mathrm{GPa}^{-1}\right)$ and assuming that the thermal expansion coefficient $\alpha^{*}$ is given by the experimental equation in Fig. 10, we can express the shear stress $S$ as a function of salt content and temperature range :

$S=\frac{e}{L_{0}} \frac{0.23 x+4.63}{31} \Delta T$

in which $S$ is given in $\mathrm{MPa}$ and $\mathrm{x}$ is the salt content $(\% \mathrm{~W})$.

To assess the possibility of damage, let us make the following assumptions which are conservative on the side of maximizing such possibility:

- Salt content $x=30 \%$ (by mass). This value is above the maximum possible in the Ançã which is of $22 \%$ for $\mathrm{NaCl}, 26 \%$ for $\mathrm{Na}_{2} \mathrm{SO}_{4}$ and $23 \%$ for $\mathrm{NaNO}_{3}$. This maximum salt content is unlikely to exist in the bulk stone, but it could be reached in the surface layer. Note that using the linear relationship in Fig. 10, instead of a second-order function such as the one given by Larsen and Nielsen's model, is also conservative on the side of maximum damage

- Temperature range $\Delta \mathrm{T}=30^{\circ} \mathrm{C}$. As seen in the previous section, if we consider the compressive strength of the Ançã, microscopic damage will start when the temperature range reaches $15^{\circ} \mathrm{C}$ for $\mathrm{Na}_{2} \mathrm{SO}_{4}, 20^{\circ} \mathrm{C}$ for $\mathrm{NaNO}_{3}$ and $30^{\circ} \mathrm{C}$ for $\mathrm{NaCl}$. Therefore, considering the three studied salts, $30^{\circ} \mathrm{C}$ is the highest temperature range that salt contaminated Ançã can tolerate without microscopic damage occurring. Note that in countries such as Portugal, this temperature range can be achieved both daily and seasonally, on facades exposed to sunlight (de la Rosa et al. 2013, RCCTE 2006, Diaz Gonçalves et al. 2015).

- Relationship $e / L_{0}=0.1$. This is highly conservative because Ançã laminae are usually just a fraction of $\mathrm{mm}$ thick and, therefore, $e$ will hardly be just ten times smaller than $L_{0}$ (Fig. 3).

For $x=30 \%, \Delta T=30^{\circ} \mathrm{C}$ and $e / L_{0}=0.1$, a shear stress $S=1.1 \mathrm{MPa}$ would be obtained from Eq. 23 , which is lower than the tensile strength of the Ançã (Table 1). This shear stress is, therefore, much lower than the shear strength of the Ançã. Indeed, the shear strength of limestones is higher than their tensile strength 
(Din et al. 1993). This means that not even in the extreme conditions we have considered will thermal expansion be able to cause detachment of the surface layer, i.e. delamination, of the Ançã. Delamination is a common feature of this stone, as illustrated in Fig. 3, but it can be due to salt crystallization, as shown elsewhere (Diaz Gonçalves and Brito 2014, Brito et al. 2015).

\section{Further research}

The predictions presented above have uncertainties associated to how well the models and their parameters are able to represent the complex real-world salt decay systems and their properties. We counteracted these uncertainties, whenever possible, by choosing conservative options, i.e., options that err on the side of caution. Nevertheless, to enhance the accuracy of predictions, further research should address the following matters.

- It is vital to have accessible, reliable and consistent values for the mechanical (strength, elastic and thermal) properties of materials and salts relevant to cultural heritage. This could be achieved by creating a specific database or by extending existing ones. In the field of material science, for eg., efforts are currently being done to chart the complete elastic properties of thousands of inorganic crystalline compounds trough a consistent computation methodology (de Jong et al. 2015). A similar effort would be valuable in the field of cultural heritage.

- The effect temperature may have on such mechanical properties needs further investigation.

- Also requiring investigation is the possible influence that salt content and salt cementing effect can have, for different salts, on the mechanical properties of porous building materials.

- The impact of the rate of temperature change, rather than the temperature range, needs further clarification too. Wellman and Wilson (1965) and Cooke \& Smalley (1968) defended that the rate is more relevant than the range, but this hypothesis has not yet been developed. However, the rate of change would allow distinguishing, for example, daily from seasonal temperature variations. It would also allow consideration of viscoelastic effects, such as creep and relaxation. Through these effects, materials could tolerate higher temperature ranges if they build slowly over a long period, which seems reasonable.

- Fatigue effects also deserve attention. By these, small temperature loads that otherwise would not lead to damage might do so when they are repeatedly applied to the material.

\section{Conclusions and perspectives}

This work predicts that thermal expansion of salt crystals can cause damage to Ançã limestone. It is a type of damage that starts at the microscopic level and will manifest as loss of cohesion of the stone (powdering, disaggregation, etc.). To prevent it, measures to reduce temperature loads, such as shading of façades, could be considered.

As shown experimentally, the linear thermal expansion coefficient of the Ançã can be significantly increased by any of the three tested salts. For example, when the stone has $5 \%$ salt content its thermal expansion will be $25 \%$ greater than when it is free of salt. However, in spite of its influence, thermal expansion is unlikely to cause exfoliation of salt loaded layers in the Ançã. The reason is that damage of microscopic origin will take place at a smaller temperature range than would be needed to build high enough shear stress between the surface layer and the bulk stone. 
Also interestingly, the variation of the thermal expansion coefficient of the Ançã with salt content was approximately linear irrespective of the type of salt. However, before assuming this type of linear relationship for a different range of salts, it is necessary to confirm that their average coefficient of linear thermal expansion has similar values. Indeed, crystals may have different thermal expansion in different crystallographic axes. But their overall behavior can be analogous if they have similar average thermal expansion, as it happened here for halite, thenardite and nitratite, because in a porous network crystals are randomly oriented.

To predict how the thermal expansion coefficient varies with salt content, the model put forward by Larsen and Nielsen's (1990) could also be an alternative. However, this model is in poor agreement with our experimental data for Ançã limestone with $\mathrm{NaCl}, \mathrm{Na}_{2} \mathrm{SO}_{4}$ or $\mathrm{NaNO}_{3}$.

Future research should investigate whether the conclusions of this work can be extended to other salts and porous materials. It should also seek to refine the mathematical models, in order to have a more accurate idea of the temperature ranges that will trigger decay. The effect of temperature on the mechanical properties of salts and materials, as well as that of salt content and type on the properties of materials, are points that need to be addressed. Future work has to investigate also the relevancy that creep, relaxation and fatigue may have on the decay process. This effort needs to include experimental simulations, which are badly missing. It should also include the creation or expansion of databases of the mechanical properties of salts and materials relevant for built heritage.

Conservators should become involved in the research process already at this stage. As ultimate users, they are in a privileged position to help discussing research aims, so that resources can be focused on what is relevant for practice. They may also provide valuable information, for eg., on decay patterns, temperature ranges and rates of change, as well as on which salts and salt mixtures are the most relevant for certain region or country.

\section{Acknowledgements}

This work was performed under the research project DRYMASS (ref. PTDC/ECM/100553/2008) which is supported by national funds through the Fundação para a Ciência e a Tecnologia (FCT) and LNEC. The authors are grateful to Luís Nunes for his support on the thermal expansion and MIP measurements, José Costa for assisting in the preparation of the specimens, Kirsten Linnow for helping find the values of some coefficients of thermal expansion, Graça Tomé for her editorial suggestions and Andrea Hamilton for reviewing the article. Thanks are also due to the anonymous reviewers of this article, for their valuable comments.

\section{References}

Allan, N. L., Rohl, A. L., Gay, D. H., Catlow, C. R. A., Davey, R. J. \& Mackrodt, W. C. 1993. Calculated bulk and surface properties of sulphates. Faraday Discussions, 95: 273-280.

Arbeck, D., Haussuhl, E., Vinograd, V.L., Winkler, B., Paulsen, N., Haussuhl, S., Milman, V. \& Gale, J.D. 2012. Elastic stiffness coefficients of thenardite and their pressure and temperature dependence. Zeitschrift fur Kristallographie / New Crystal Structures, 227: 503-513.

ASTM International. 2004. Standard test method for determination of pore volume and pore volume distribution of soil and rock by mercury intrusion porosimetry. ASTM standard D 4404-84. 
Bass, J.D. 1995. Elasticity of Minerals, Glasses, and Melts, in Mineral Physics \& Crystallography: A Handbook of Physical Constants. Washington D.C.: American Geophysical Union. DOI: 10.1029/RF002p0045.

Benavente, D., Brimblecombe, P., \& Grossi, C.M. 2008. Salt weathering and climate change. In Colombini, M.P. \& Tassi, L. eds. New Trends in Analytical, Environmental and Cultural Heritage Chemistry. pp. 277286. ISBN 978-81-7895-343-4.

Birch, F., Schairer, J. F., \& Spicer, H. C. (Eds.). (1942). Handbook of physical constants (Vol. 36). Geological Society of America, Special Papers, Number 36.

Brito, V., \& Diaz Gonçalves, T. 2013. Drying Kinetics of Porous Stones in the Presence of $\mathrm{NaCl}$ and NaNO3: Experimental Assessment of the Factors Affecting Liquid and Vapour Transport. Transport in porous media, 100(2): 193-210.

Brito, V., Saidov, T. A., Gonçalves, T. D., \& Pel, L. 2015. Delamination of Ançã limestone due to sodium sulphate under different environmental conditions as studied by nuclear magnetic resonance. Journal of Building Physics, 38(5): 465-482.

Castro, E., Delgado Rodrigues, J. \& Tavares Cravo, M.R. 1975. Conservação de pedras em edifícios de interesse histórioco ou artístico. 6o relatório: estudo do calcário dum retábulo da Sé Velha de Coimbra e de calcários de pedreiras da região (Conservation of stones in buildings with historical or artistic interest. 6th report: Study of the limestone of an altarpiece of Sé Velha, Coimbra, and of limestones from quarries in the region). Lisboa: Laboratório Nacional de Engenharia Civil (LNEC). Procº 54/13/4388 [in Portuguese].

Chapman, R.W. 1980. Salt weathering by sodium chloride in the Saudi Arabian desert. American Journal of Science, 280(2): 116-129.

Charola, A.E. \& Weber, J. 1992. The hydration-dehydration mechanism of sodium sulphate. In: 7th International Congress on Deterioration and Conservation of Stone, Proc. Lisbon: LNEC, pp. 581-590.

Cooke, R. U. \& Smalley, I. J. 1968. Salt weathering in deserts. Nature, 220: 1226-1227.

Costa, D. \& Delgado Rodrigues, J. 2012. Consolidation of a porous limestone with nanolime. In: 12th International Congress on the Deterioration and Conservation of Stone, Proc. Available at: http://iscs.icomos.org/pdf-files/NewYorkConf/costdelg.pdf [Accessed 11 September 2015].

de Jong, M., Chen, W., Angsten, T., Jain, A., Notestine, R., Gamst, A., ... \& Asta, M. (2015). Charting the complete elastic properties of inorganic crystalline compounds. Scientific Data, 2: 150009.

de la Rosa, J. P. M., Porcel, M. C., \& Warke, P. A. 2013. Mapping stone surface temperature fluctuations: Implications for lichen distribution and biomodification on historic stone surfaces. Journal of Cultural Heritage, 14(4): 346-353.

Derluyn, H. 2012. Salt transport and crystallization in porous limestone: neutron-X-ray imaging and poromechanical modeling. Doctoral dissertation, Katholieke Universiteit Leuven.

Diaz Gonçalves, T., \& Brito, V. 2014. Alteration kinetics of natural stones due to sodium sulphate crystallization: can reality match experimental simulations?. Environmental Geology, 72(6): 1789-1799.

Diaz Gonçalves, T., Brito, V., Vidigal, F., Matias, L., \& Faria, P. 2015. Evaporation from Porous Building Materials and Its Cooling Potential. Journal of Materials in Civil Engineering 27 (8): 04014222. 
Diaz Gonçalves, T., Delgado Rodrigues, J., Abreu, M.M., Esteves. A.M. \& Santos Silva. A. 2006. Causes of salt decay and repair of plasters and renders of five historic buildings in Portugal. In: Conference Heritage, Weathering and Conservation, Proc. Madrid: Taylor and Francis / Balkema, pp. 273-284.

Din, F., Rafiq, M., \& Mohammad, N. 1993. Strength properties of various building stones of NWFP Pakistan. Geol. Bull. Univ. Peshawar, 26, 119-126. Available at: http://nceg.uop.edu.pk/GeologicalBulletin/Vol-26-1993/Vol-26-1993-Paper11.pdf [Accessed 21 July 2015].

Doehne, E. \& Price, A. C. 2010. Stone conservation: an overview of current research. $2^{\text {nd }}$ edition. The Getty Conservation Institute, Los Angeles. Available at: http://www.getty.edu/conservation/publications_resources/pdf_publications/pdf/stoneconservation.pdf [Accessed 11 September 2015].

Espinosa-Marzal, R. M., \& Scherer, G. W. 2009. Crystallization pressure exerted by in-pore confined crystals. In: Poromechanics IV - 4th Biot Conference on Poromechanics, Proc. Lancaster: DE-Stech Publications, pp. 1013-1018.

Evans, I.S. 1969-1970. Salt crystallization and rock weathering: a review, Revue de Géomorphologie Dynamique, 4: 153-177.

Ferreira Pinto, A. P. (2002). Conservação de pedras carbonatadas. Estudo e selecção de tratamentos. PhD Thesis, Universidade de Lisboa [in Portuguese].

Flatt, R. J., Caruso, F., Sanchez, A. M. A., \& Scherer, G. W. 2014. Chemo-mechanics of salt damage in stone. Nature communications, 5: 4823.

Goudie, A. \& Viles, H. 1997. Salt Weathering Hazard. UK: John Wiley \& Sons.

Goudie, A. S. 1974. Further experimental investigation of rock weathering by salt and other mechanical processes. Zeitschrift für Geomorphologie Supplementband, 21: 1-12.

GSE (1970-1979) Isothermal compressibility. In: The Great Soviet Encyclopedia (GSE), 3rd Edition. Available at: http://encyclopedia2.thefreedictionary.com/Isothermal+compressibility. [Accessed April 22, 2015].

Ibrahim, M., Ramachandran, V., Sarangapani, K. \& Srinivasan R. 1986. Thermal expansion of sodium nitrate (I). Journal of Physics and Chemistry of Solids, 47: 517-520.

Johannessen, C. L., Feiereisen, J. J., \& Wells, A. N. 1982. Weathering of ocean cliffs by salt expansion in a mid-latitude coastal environment. Shore and Beach, 50: 26-34.

Johnston, J.H. 1973. Salt weathering processes in the McMurdo dry valley regions of South Victoria Land, Antarctica. New Zealand journal of geology and geophysics, 16(2): 221-224.

Krishnan, R. S., Srinivasan, R., \& Devanarayanan, S. 1979. Thermal Expansion of Crystals. England: Pergamon.

Larsen, E. S. \& Nielsen, C.B. 1990. Decay of brick due to salt. Materials and Structures, 23: 16-25.

Liang, W. G., Xu, S., Mo, J., Wu, D., \& Zhang, C. 2010. Test study of strain rate effects on mechanical performances of salt rock. Chinese Journal of Rock Mechanics and Engineering, 29(1): 43-50.

Lubelli, B., van Hees, R. P., \& Groot, C. J. 2004. The role of sea salts in the occurrence of different damage mechanisms and decay patterns on brick masonry. Construction and Building Materials, 18(2): 119-124. 
Lurie, J. 1975. Handbook of Analytical Chemistry. Moscow: Mir Publishers.

MacMahon, D., Sandberg, P., Folliard, K. \& Mehta, P. 1992. Deterioration mechanisms of sodium sulphate. In: 7th International Congress on Deterioration and Conservation of Stone, Proc. Lisbon: LNEC, pp. 705-714.

Nielsen, C.B. 1988. Thermisk deformation og svind af saltholdige teglsten' (Thermal deformation and shrinkage of salt loaded bricks). Lyngby: Laboratoriet for Bygningsmaterialer, Danmarks Tekniske Hojskole. Teknisk rapport 182/88 [in Danish].

Obika, B., R.J. Freer-Hewish \& Newill D. 1992. Physico-chemical aspects of soluble salt damage of thin bituminous surfacing. In:. International Conference on the Implications of Ground Chemistry and Microbiology for Construction, Preprints. University of Bristol.

RCCTE. 2006. Regulamento das Características de Comportamento Térmico dos Edifícios (Regulation on the Characteristics for Thermal Performance of Buildings). Decreto-Lei no80/2006 de 4, pp. 2468-2413 [in Portuguese].

RILEM TC 25-PEM. 1980. Recommended tests to measure the deterioration of stone and to assess the effectiveness of treatment methods. Materials and Structures, 13: 176-179 (test No. I.1 "Porosity accessible to water"), 194-197 (test No. II.1 "Saturation coefficient", 197-199 (test No. II.2 "Coefficient of water vapour conductivity"), 208-209 (test No. II.6 "Water absorption coefficient (capillarity)".

Robertson, E.C., Robie, R.A. \& Books, K.G. 1958. Physical properties of salt, anhydrite and gypsum: preliminary report. U.S. Geological Survey, United States of America. Trace Elements Memorandum 1048. Available at: http://pubs.usgs.gov/tem/1048/report.pdf. [Accessed 31 July, 2014].

Rodrigues, M. 1998. Estudo da degradação da pedra em monumentos de Coimbra. (Study about the degradation of stone monuments in Coimbra). Lisboa: LNEC. Relatório de estágio realizado no âmbito do Concurso no1/PRODEP/98 [in Portuguese].

Rodriguez-Navarro, C., Doehne, E., \& Sebastian, E. 2000. How does sodium sulphate crystallize? Implications for the decay and testing of building materials. Cement and concrete research, 30(10): 15271534.

Rossi-Manaresi. R. \& Tucci, A. 1991 Pore structure and the disruptive or cementing effect of salt crystallization in various types of stones. Studies in Conservation 36: 53-58.

Sabbioni C., Brimblecombe P. \& Cassar M. 2010. The Atlas of Climate Change Impact on European Cultural Heritage: Scientific Analysis and Management Strategies. The Anthem-European Union Series.

Schaffer, R.J. 1932. The weathering of natural building stones. His Majesty's Stationery Office, London. Building Research Special Report 18. Reprinted, with slight amendments, 1933.

Schwarz, H.-J. a. Halite. Available at: http://193.175.110.91/saltwiki/index.php/Halite [Accessed 1 August, 2015].

Schwarz, H.-J. b. Nitonatrite. Available at: http://193.175.110.91/saltwiki/index.php/ Nitronatrite [Accessed 1 August, 2015].

Schwarz, H.-J., Steiger, M. \& Müller, T. Thenardite. Available at: http://193.175.110.91 /saltwiki/index.php/Thenardite [Accessed 1 August, 2015]. 
The Version of Record of this manuscript has been published and is available in STUDIES IN CONSERVATION, 2016, http://www.tandfonline.com/10.1080/00393630.2016.1140860

Skinner, B.J. 1966. Thermal Expansion. In: Clark, S.P. ed. Handbook of Physical Constants. Revised Edition. Geological Society of America, Memoir 97, pp. 75-96.

Wellman, H. W., \& Wilson, A. T. 1965. Salt weathering, a neglected geological erosive agent in coastal and arid environments. Nature, 205: 1097-1098. 
The Version of Record of this manuscript has been published and is available in STUDIES IN CONSERVATION, 2016, http://www.tandfonline.com/10.1080/00393630.2016.1140860

\section{Appendix 1}

Table A.1 - Raw data from the thermal expansion measurements obtained for the control specimens (pure water)

\begin{tabular}{|c|c|c|c|c|c|c|}
\hline Ref. & Specimen & Salt content (\%) & $\mathrm{L}_{0}(\mathrm{~mm})$ & $\Delta \mathrm{L}(\mathrm{mm})$ & $\mathrm{T}\left({ }^{\circ} \mathrm{C}\right)$ & $\alpha \times 10^{-6}\left({ }^{\circ} \mathrm{C}^{-1}\right)$ \\
\hline \multirow{6}{*}{$\begin{array}{l}\text { Water } \\
\text { (test T1) }\end{array}$} & \multirow{6}{*}{ T1.W.1 } & \multirow{6}{*}{0.0} & \multirow{6}{*}{100.0} & 0.000 & 23.6 & \multirow{6}{*}{4.87} \\
\hline & & & & 0.006 & 36.8 & \\
\hline & & & & 0.011 & 46.5 & \\
\hline & & & & 0.017 & 59.4 & \\
\hline & & & & 0.023 & 71.3 & \\
\hline & & & & 0.029 & 83.2 & \\
\hline \multirow{6}{*}{$\begin{array}{l}\text { Water } \\
\text { (test T1) }\end{array}$} & \multirow{6}{*}{ T1.W.2 } & \multirow{6}{*}{0.0} & \multirow{6}{*}{100.2} & 0.000 & 19.2 & \multirow{6}{*}{4.42} \\
\hline & & & & 0.006 & 33.0 & \\
\hline & & & & 0.012 & 45.5 & \\
\hline & & & & 0.018 & 59.3 & \\
\hline & & & & 0.024 & 72.3 & \\
\hline & & & & 0.029 & 85.4 & \\
\hline \multirow{6}{*}{$\begin{array}{l}\text { Water } \\
\text { (test T2) }\end{array}$} & \multirow{6}{*}{ T2.W.1 } & \multirow{6}{*}{0.0} & \multirow{6}{*}{99.7} & 0.000 & 20.1 & \multirow{6}{*}{5.08} \\
\hline & & & & 0.006 & 33.0 & \\
\hline & & & & 0.012 & 45.6 & \\
\hline & & & & 0.018 & 60.6 & \\
\hline & & & & 0.027 & 76.1 & \\
\hline & & & & 0.037 & 91.7 & \\
\hline \multirow{6}{*}{$\begin{array}{l}\text { Water } \\
\text { (test T2) }\end{array}$} & \multirow{6}{*}{ T2.W.2 } & \multirow{6}{*}{0.0} & \multirow{6}{*}{100.3} & 0.000 & 20.6 & \multirow{6}{*}{4.47} \\
\hline & & & & 0.005 & 33.3 & \\
\hline & & & & 0.010 & 45.8 & \\
\hline & & & & 0.016 & 61.2 & \\
\hline & & & & 0.024 & 77.2 & \\
\hline & & & & 0.033 & 93.3 & \\
\hline
\end{tabular}


The Version of Record of this manuscript has been published and is available in STUDIES IN CONSERVATION, 2016, http://www.tandfonline.com/10.1080/00393630.2016.1140860

Table A.2 - Raw data from the thermal expansion measurements obtained for $\mathrm{Na}_{2} \mathrm{SO}_{4}$

\begin{tabular}{|c|c|c|c|c|c|c|}
\hline Ref. & Specimen & Salt content (\%) & $\mathrm{L}_{0}(\mathrm{~mm})$ & $\mathrm{T}\left({ }^{\circ} \mathrm{C}\right)$ & $\Delta \mathrm{L}(\mathrm{mm})$ & $\alpha \times 10^{-6}\left({ }^{\circ} \mathrm{C}^{-1}\right)$ \\
\hline \multirow{6}{*}{$\begin{array}{l}\mathrm{Na}_{2} \mathrm{SO}_{4} \\
(\text { test T1) }\end{array}$} & \multirow{6}{*}{ T1.SO.1 } & \multirow{6}{*}{2.4} & \multirow{6}{*}{100.0} & 20.5 & 0.000 & \multirow{6}{*}{5.32} \\
\hline & & & & 32.8 & 0.007 & \\
\hline & & & & 45.6 & 0.014 & \\
\hline & & & & 59.5 & 0.020 & \\
\hline & & & & 72.7 & 0.028 & \\
\hline & & & & 85.8 & 0.035 & \\
\hline \multirow{6}{*}{$\begin{array}{l}\mathrm{Na}_{2} \mathrm{SO}_{4} \\
\text { (test T2) }\end{array}$} & \multirow{6}{*}{ T2.SO.1 } & \multirow{6}{*}{1.8} & \multirow{6}{*}{99.7} & 20.1 & 0.000 & \multirow{6}{*}{5.34} \\
\hline & & & & 33.0 & 0.010 & \\
\hline & & & & 44.3 & 0.015 & \\
\hline & & & & 57.2 & 0.020 & \\
\hline & & & & 70.7 & 0.028 & \\
\hline & & & & 84.6 & 0.036 & \\
\hline \multirow{6}{*}{$\begin{array}{l}\mathrm{Na}_{2} \mathrm{SO}_{4} \\
\text { (test T2) }\end{array}$} & \multirow{6}{*}{ T2.SO.2 } & \multirow{6}{*}{1.8} & \multirow{6}{*}{99.6} & 20.8 & 0.000 & \multirow{6}{*}{5.18} \\
\hline & & & & 32.5 & 0.006 & \\
\hline & & & & 45.5 & 0.013 & \\
\hline & & & & 60.9 & 0.020 & \\
\hline & & & & 76.8 & 0.028 & \\
\hline & & & & 93.2 & 0.038 & \\
\hline \multirow{6}{*}{$\begin{array}{l}\mathrm{Na}_{2} \mathrm{SO}_{4} \\
\text { (test T2) }\end{array}$} & \multirow{6}{*}{ T2*.SO.1 } & \multirow{6}{*}{1.7} & \multirow{6}{*}{99.4} & 21.2 & 0.000 & \multirow{6}{*}{4.92} \\
\hline & & & & 33.4 & 0.008 & \\
\hline & & & & 44.8 & 0.012 & \\
\hline & & & & 58.5 & 0.018 & \\
\hline & & & & 72.7 & 0.026 & \\
\hline & & & & 86.9 & 0.033 & \\
\hline \multirow{6}{*}{$\begin{array}{l}\mathrm{Na}_{2} \mathrm{SO}_{4} \\
\text { (test T2) }\end{array}$} & \multirow{6}{*}{ T2*.SO.2 } & \multirow{6}{*}{1.9} & \multirow{6}{*}{99.7} & 20.5 & 0.000 & \multirow{6}{*}{4.54} \\
\hline & & & & 33.5 & 0.008 & \\
\hline & & & & 45.1 & 0.013 & \\
\hline & & & & 58.9 & 0.018 & \\
\hline & & & & 73.3 & 0.024 & \\
\hline & & & & 87.9 & 0.032 & \\
\hline
\end{tabular}


The Version of Record of this manuscript has been published and is available in STUDIES IN CONSERVATION, 2016, http://www.tandfonline.com/10.1080/00393630.2016.1140860

Table A.3 - Raw data from the thermal expansion measurements obtained for $\mathrm{NaCl}$

\begin{tabular}{|c|c|c|c|c|c|c|}
\hline Ref. & Specimen & Salt content (\%) & $\mathrm{L}_{0}(\mathrm{~mm})$ & $\mathrm{T}\left({ }^{\circ} \mathrm{C}\right)$ & $\Delta \mathrm{L}(\mathrm{mm})$ & $\alpha \times 10^{-6}\left({ }^{\circ} \mathrm{C}^{-1}\right)$ \\
\hline \multirow{6}{*}{$\begin{array}{l}\mathrm{NaCl} \\
\text { (test T1) }\end{array}$} & \multirow{6}{*}{ T1.Cl.1 } & \multirow{6}{*}{3.8} & \multirow{6}{*}{100.5} & 17.7 & 0.000 & \multirow{6}{*}{5.40} \\
\hline & & & & 33.0 & 0.008 & \\
\hline & & & & 45.0 & 0.014 & \\
\hline & & & & 58.6 & 0.021 & \\
\hline & & & & 71.1 & 0.028 & \\
\hline & & & & 83.6 & 0.036 & \\
\hline \multirow{6}{*}{$\begin{array}{l}\mathrm{NaCl} \\
\text { (test T1) }\end{array}$} & \multirow{6}{*}{ T1.Cl.2 } & \multirow{6}{*}{3.8} & \multirow{6}{*}{100.4} & 21.9 & 0.000 & \multirow{6}{*}{5.35} \\
\hline & & & & 32.4 & 0.004 & \\
\hline & & & & 46.3 & 0.011 & \\
\hline & & & & 62.2 & 0.021 & \\
\hline & & & & 78.4 & 0.029 & \\
\hline & & & & 93.8 & 0.038 & \\
\hline \multirow{6}{*}{$\begin{array}{l}\mathrm{NaCl} \\
\text { (test T2) }\end{array}$} & \multirow{6}{*}{ T2.Cl.1 } & \multirow{6}{*}{3.2} & \multirow{6}{*}{100.5} & 21.0 & 0.000 & \multirow{6}{*}{4.88} \\
\hline & & & & 33.5 & 0.006 & \\
\hline & & & & 44.2 & 0.011 & \\
\hline & & & & 57.6 & 0.017 & \\
\hline & & & & 71.5 & 0.024 & \\
\hline & & & & 85.4 & 0.032 & \\
\hline \multirow{6}{*}{$\begin{array}{l}\mathrm{NaCl} \\
\text { (test T2) }\end{array}$} & \multirow{6}{*}{ T2.Cl.2 } & \multirow{6}{*}{3.1} & \multirow{6}{*}{100.6} & 19.7 & 0.000 & \multirow{6}{*}{5.65} \\
\hline & & & & 33.7 & 0.008 & \\
\hline & & & & 44.9 & 0.014 & \\
\hline & & & & 57.6 & 0.020 & \\
\hline & & & & 70.9 & 0.029 & \\
\hline & & & & 84.3 & 0.037 & \\
\hline \multirow{6}{*}{$\begin{array}{l}\mathrm{NaCl} \\
\text { (test T2) }\end{array}$} & \multirow{6}{*}{ T2*.Cl.1 } & \multirow{6}{*}{2.9} & \multirow{6}{*}{100.0} & 20.8 & 0.000 & \multirow{6}{*}{5.93} \\
\hline & & & & 31.9 & 0.007 & \\
\hline & & & & 44.1 & 0.014 & \\
\hline & & & & 57.2 & 0.022 & \\
\hline & & & & 70.6 & 0.029 & \\
\hline & & & & 84.0 & 0.038 & \\
\hline \multirow{6}{*}{$\begin{array}{l}\mathrm{NaCl} \\
\text { (test T2) }\end{array}$} & \multirow{6}{*}{$\mathrm{T}^{*} . \mathrm{Cl} .2$} & & & 22.5 & 0.000 & \\
\hline & & & & 34.2 & 0.006 & \\
\hline & & 3.0 & 100.1 & 43.8 & 0.011 & 511 \\
\hline & & & 100. & 57.0 & 0.017 & (.T \\
\hline & & & & 70.7 & 0.024 & \\
\hline & & & & 84.1 & 0.032 & \\
\hline
\end{tabular}


The Version of Record of this manuscript has been published and is available in STUDIES IN CONSERVATION, 2016, http://www.tandfonline.com/10.1080/00393630.2016.1140860

Table A.4 - Raw data from the thermal expansion measurements obtained for $\mathrm{NaNO}_{3}$

\begin{tabular}{|c|c|c|c|c|c|c|}
\hline Ref. & Specimen & Salt content (\%) & $\mathrm{L}_{0}(\mathrm{~mm})$ & $\mathrm{T}\left({ }^{\circ} \mathrm{C}\right)$ & $\Delta \mathrm{L}(\mathrm{mm})$ & $\alpha \times 10^{-6}\left({ }^{\circ} \mathrm{C}^{-1}\right)$ \\
\hline \multirow{6}{*}{$\begin{array}{l}\mathrm{NaNO}_{3} \\
\text { (test T1) }\end{array}$} & \multirow{6}{*}{ T1.NO.1 } & \multirow{6}{*}{8.5} & \multirow{6}{*}{100.9} & 25.9 & 0.000 & \multirow{6}{*}{6.51} \\
\hline & & & & 34.0 & 0.005 & \\
\hline & & & & 45.6 & 0.013 & \\
\hline & & & & 59.2 & 0.022 & \\
\hline & & & & 71.6 & 0.030 & \\
\hline & & & & 84.2 & 0.038 & \\
\hline \multirow{6}{*}{$\begin{array}{l}\mathrm{NaNO}_{3} \\
\text { (test T1) }\end{array}$} & \multirow{6}{*}{ T1.NO.2 } & \multirow{6}{*}{8.1} & \multirow{6}{*}{101.0} & 19.0 & 0.000 & \multirow{6}{*}{6.55} \\
\hline & & & & 33.9 & 0.008 & \\
\hline & & & & 46.4 & 0.016 & \\
\hline & & & & 61.3 & 0.027 & \\
\hline & & & & 75.0 & 0.036 & \\
\hline & & & & 89.6 & 0.046 & \\
\hline
\end{tabular}


The Version of Record of this manuscript has been published and is available in STUDIES IN CONSERVATION, 2016, http://www.tandfonline.com/10.1080/00393630.2016.1140860

Table A.5 - Raw data from the thermal expansion measurements obtained for the blank specimens

\begin{tabular}{|c|c|c|c|c|c|c|}
\hline Ref. & Specimen & Salt content (\%) & $\mathrm{L}_{0}(\mathrm{~mm})$ & $\mathrm{T}\left({ }^{\circ} \mathrm{C}\right)$ & $\Delta \mathrm{L}(\mathrm{mm})$ & $\alpha \times 10^{-6}\left({ }^{\circ} \mathrm{C}^{-1}\right)$ \\
\hline \multirow{6}{*}{$\begin{array}{l}\text { Blank } \\
\text { specimens }\end{array}$} & \multirow{6}{*}{ B1 } & \multirow{6}{*}{0.0} & \multirow{6}{*}{99.6} & 20.0 & 0.000 & \multirow{6}{*}{4.44} \\
\hline & & & & 33.5 & 0.007 & \\
\hline & & & & 44.0 & 0.011 & \\
\hline & & & & 56.2 & 0.016 & \\
\hline & & & & 68.3 & 0.022 & \\
\hline & & & & 80.4 & 0.027 & \\
\hline \multirow{6}{*}{$\begin{array}{l}\text { Blank } \\
\text { specimens }\end{array}$} & \multirow{6}{*}{ B2 } & \multirow{6}{*}{0.0} & \multirow{6}{*}{99.4} & 20.6 & 0.000 & \multirow{6}{*}{4.81} \\
\hline & & & & 33.8 & 0.006 & \\
\hline & & & & 43.9 & 0.011 & \\
\hline & & & & 56.3 & 0.017 & \\
\hline & & & & 68.5 & 0.022 & \\
\hline & & & & 80.6 & 0.029 & \\
\hline \multirow{6}{*}{$\begin{array}{l}\text { Blank } \\
\text { specimens }\end{array}$} & \multirow{6}{*}{ B3 } & \multirow{6}{*}{0.0} & \multirow{6}{*}{99.2} & 20.8 & 0.000 & \multirow{6}{*}{4.48} \\
\hline & & & & 33.3 & 0.006 & \\
\hline & & & & 45.3 & 0.012 & \\
\hline & & & & 59.4 & 0.018 & \\
\hline & & & & 74.5 & 0.024 & \\
\hline & & & & 89.8 & 0.031 & \\
\hline \multirow{6}{*}{$\begin{array}{l}\text { Blank } \\
\text { specimens }\end{array}$} & \multirow{6}{*}{ B4 } & \multirow{6}{*}{0.0} & \multirow{6}{*}{99.4} & 20.8 & 0.000 & \multirow{6}{*}{4.13} \\
\hline & & & & 32.9 & 0.004 & \\
\hline & & & & 43.2 & 0.009 & \\
\hline & & & & 55.4 & 0.014 & \\
\hline & & & & 67.8 & 0.019 & \\
\hline & & & & 80.1 & 0.024 & \\
\hline \multirow{6}{*}{$\begin{array}{l}\text { Blank } \\
\text { specimens }\end{array}$} & \multirow{6}{*}{ B5 } & \multirow{6}{*}{0.0} & \multirow{6}{*}{99.6} & 20.2 & 0.000 & \multirow{6}{*}{4.83} \\
\hline & & & & 33.9 & 0.007 & \\
\hline & & & & 44.6 & 0.012 & \\
\hline & & & & 57.4 & 0.018 & \\
\hline & & & & 70.7 & 0.024 & \\
\hline & & & & 83.9 & 0.031 & \\
\hline \multirow{6}{*}{$\begin{array}{l}\text { Blank } \\
\text { specimens }\end{array}$} & \multirow{6}{*}{ B6 } & & & 21.6 & 0.000 & \\
\hline & & & & 34.5 & 0.007 & \\
\hline & & 0 & 995 & 44.1 & 0.011 & 166 \\
\hline & & 0.0 & 00.0 & 56.7 & 0.018 & T. \\
\hline & & & & 69.4 & 0.023 & \\
\hline & & & & 82.1 & 0.028 & \\
\hline
\end{tabular}

